\title{
Numerical modelling of micro-plasto-hydrodynamic lubrication in plane strip drawing
}

Carretta, Y.; Bech, Jakob Ilsted; Legrand, N.; Laugier, M.; Ponthot, J. P.; Boman, R.

Published in:

Tribology International

Link to article, DOI:

10.1016/j.triboint.2016.10.046

Publication date:

2017

Document Version

Peer reviewed version

Link back to DTU Orbit

Citation (APA):

Carretta, Y., Bech, J. I., Legrand, N., Laugier, M., Ponthot, J. P., \& Boman, R. (2017). Numerical modelling of micro-plasto-hydrodynamic lubrication in plane strip drawing. Tribology International, 110, 378-391.

https://doi.org/10.1016/j.triboint.2016.10.046

\section{General rights}

Copyright and moral rights for the publications made accessible in the public portal are retained by the authors and/or other copyright owners and it is a condition of accessing publications that users recognise and abide by the legal requirements associated with these rights.

- Users may download and print one copy of any publication from the public portal for the purpose of private study or research.

- You may not further distribute the material or use it for any profit-making activity or commercial gain

- You may freely distribute the URL identifying the publication in the public portal 


\title{
Numerical modelling of micro-plasto-hydrodynamic lubrication in plane strip drawing
}

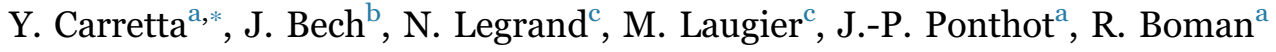 \\ a Department of Aerospace and Mechanical Engineering, University of Liège, Belgium \\ b Department of Wind Energy, Technical University of Denmark, 2800 Lyngby, Denmark \\ c ArcelorMittal Global R\& D, Maizières-les-Metz, France
}

\section{A R T I C L E I N F O}

Keywords:

Metal forming

Micro-plasto-hydrodynamic (MPH) lubrication

Finite element method

Arbitrary Lagrangian Eulerian (ALE)

formalism

\begin{abstract}
A B S T R A C T
This paper presents a new finite element model capable of predicting the onset of micro-plasto-hydrodynamic (MPH) lubrication and the amount of lubricant escaping from surface pockets in metal forming.

The present approach is divided in two steps. First, a simulation at the macroscopic level is conducted. Then, a second simulation highlighting microscopic liquid lubrication mechanisms is achieved using boundary conditions provided by the first model. These fluid-structure interaction computations are made possible through the use of the Arbitrary Lagrangian Eulerian (ALE) formalism.

The developed methodology is validated by comparison to experimental measurements conducted in plane strip drawing. The effect of physical parameters like the drawing speed, the die angle and the strip thickness reduction is investigated. The numerical results show good agreement with experiments.
\end{abstract}

\section{Introduction}

In most sheet metal forming processes, lubricants are used to reduce friction forces involved in the process. Different lubricant regimes take place depending on the operating conditions and the piezo viscous behaviour of the lubricant itself.

When the two surfaces are fully separated by the lubricant film, thick-film lubrication occurs. When the lubricant film thickness decreases to a value of the same order of magnitude as the surfaces roughness, thin-film regime occurs and asperities have an effect on the lubricant flow. Once the film thickness decreases even further, mixed lubrication regime takes place. There, both solid-to-solid and fluid-tosolid contact conditions happen and friction is the mixture of these two components. Finally, when the contact load is only supported by asperities of the contacting surfaces, the boundary lubrication regime is reached.

When the tool-workpiece contact turns severe, some lubricant can be trapped in isolated surface cavities. Experimental observation suggests that oil trapped in these cavities can behave as a source of lubricant when the pressure increases even more, to reduce friction. Mizuno and Okamoto [1] observed this phenomenon in compression friction tests. Strip surface analysis performed after the experiments showed discrete oil pits at low speed and small viscosity. At higher sliding speed and viscosity, these pits decreased in size meaning that the lubricant flew out of the cavities. Their experimental results also showed an increase of the mean shear stress with the product of the sliding velocity and the viscosity of the oil. This means that some hydrodynamic phenomenon took place at the interface. They termed this phenomenon "micro-plasto-hydrodynamic" (MPH) lubrication.

Azushima et al. [2] designed a test rig to study these lubricant flows in strip drawing. Through a tool made of glass they observed the behaviour of macroscopic pyramidal indentations filled with lubricant. While the strip was pulled through the die, they witnessed lubricant being squeezed out from the oil pockets at the front and at the rear of the pyramidal cavities. They showed that lubricant escapes were influenced by strip thickness reduction, drawing speed, and lubricant viscosity.

Using a similar test rig, Bech et al. [3] investigated the effect of the die angle, back tension, strain-hardening of the strip and friction conditions along the lower die. Also, they observed a strip-drawing force decrease as the lubricant escaped from cavities. Moreover after deformation, a strip-surface roughness increase was visible where a lubricant film developed between the strip and the tool.

Other experimental studies quantifying the effect of cavity volume and pocket shape, in plane strip drawing, were conducted respectively by Sørensen et al. [4] and Shimizu et al. [5].

\footnotetext{
* Corresponding author.

E-mail addresses: y.carretta@ulg.ac.be (Y. Carretta), jakb@dtu.dk (J. Bech), nicolas.legrand@arcelormittal.com (N. Legrand), maxime.laugier@arcelormittal.com (M. Laugier), JP.Ponthot@ulg.ac.be (J.-P. Ponthot), r.boman@ulg.ac.be (R. Boman).
} 


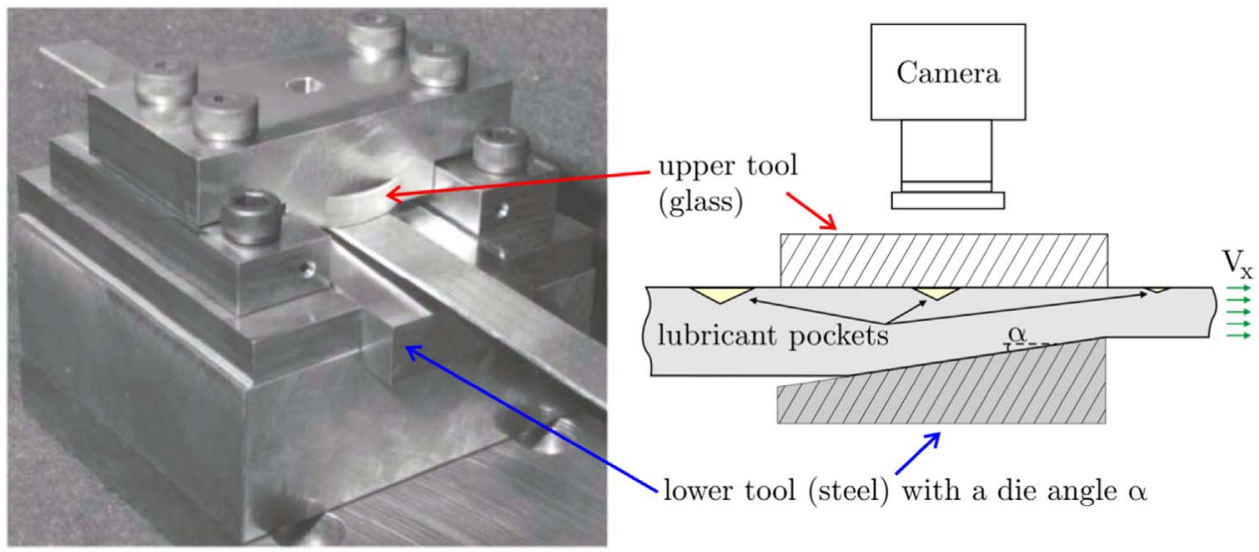

Fig. 1. Left: Experimental setup used by Bech to observe MPH lubrication. Right: schematic view of the setup. (2-column fitting image).

Azushima [6] used a similar experimental device to achieve direct observation at the asperity level through a microscope. He observed microroughening of the plateaus caused by lubricant drawn out of the pits. Ahmed and Sutcliffe [7] conducted strip drawing and rolling experiments highlighting the occurrence of MPH lubrication in these two processes at the microscopic scale. Aslo, Laugier et al. [8] computed equivalent friction coefficient values based on process experimental measurements (rolling load and forward slip) for different strip thickness reduction levels. They observed a decrease of these friction coefficient values with the strip thickness reduction suggesting the occurrence of MPH lubrication.

Lo and Horng [9] carried out compression sliding tests at a constant pressure on a strip undergoing no bulk plastic strain. From the analysis of the surface topography performed after the tests they observed deformations of the pits in a centripetal mode: lubricant flew out of the cavities while their depth was not changed.

There exist only a few models dealing with MPH. Lo and Wilson [10] developed equations to model lubricant outflows at the rear of lubricant cavities. Even though this model represents some features of MPH lubrication, it suffers from several limitations (rigid plastic material, constant slope of the cavity edge during the deformation, etc.). These equations were then extended by Sutcliffe et al. [11] to investigate evolution of micro-pits during strip rolling and drawing due to MPH lubrication.

Shimizu et al. [12] used a rigid-viscoplastic finite element (FE) formulation to model plane strip drawing experiments. A two-step procedure was developed. In the first step, velocities of the nodes on the edges of the macroscopic lubricant cavity were recorded assuming that the material of the strip and the cavity were identical. Then, during the second step, these boundary conditions were applied on the edges of a cavity filled with lubricant. Therefore, fluid and solid parts were not accounted for at the same time during the simulation.

Dubois and coworkers [13-15] used a fluid-solid coupling approach implemented in a FE software to model lubricant exchanges between consecutive pockets in plane strip drawing. The model limitation is the direct connexion between two consecutive cavities from the beginning of the simulations. This does not allow them to determine the onset of the MPH flows. Moreover, the section of the link is not calculated by the simulation. This team also conducted some experimental work: their experimental device was similar to the one of Bech [3] using triangular sectioned grooves as lubricant reservoirs [14]. They employed a new method based on the estimation of roughness peaks curvature estimation $[16,17]$ to identify the regions where local changes due to MPH lubrication occurred [18]. Very recently, several experimental analyses [19-21] showed that surface texture can reduce friction in sheet metal forming compared to conventionally polished tools.

Despite these experimental observations and these models, the knowledge of the lubricant permeation mechanisms is still very primitive. To get a better understanding of the phenomenon, new finite element simulations are carried out. This paper presents a fluid structure interaction (FSI) model capable of predicting the onset of MPH lubrication and the amount of lubricant escape. This method was developed in Metafor [22], an in-house FE code including large strains, and then used to numerically reproduce the experiments conducted by Bech et al. [3] in plane strip drawing.

The numerical model is presented in Section 2. The model is able to predict the backward and forward lubricant escapes from the pocket and shows good agreement with experimental observations carried out by Bech.

The influence of the die angle, the drawing speed and the strip thickness reduction is also investigated. Numerical results presented in Section 3 exhibit good agreements with Bech's experiments.

\section{Numerical modelling of micro plastohydrodynamic lubrication in plane strip drawing}

\subsection{Introduction}

This chapter presents a FE model developed to numerically reproduce the experiments conducted by Bech. As mentioned in the introduction, Bech [3] pointed out MPH lubrication flows using plane strip drawing. The experimental setup he used is represented in Fig. 1. He performed pyramidal indentations on a $1.95 \mathrm{~mm}$ thick aluminium strip and filled them with lubricant before drawing the strip through the die at a given speed $V_{x}$. Thanks to a tool made of glass Bech observed the behaviour of the lubricant cavities while pulling the strip through the tool.

Bech investigated the effect of the die angle, the back tension, the strip material behaviour and the friction between the lower surface of the strip and the tool. Fig. 2 shows the marks left by the lubricant around the pocket after the drawing process. These marks are essentially oriented in the drawing direction but in some cases transverse flows occur (see for example tests labelled A1 - B5 - B7 C5 - C7 in Fig. 2). The phenomenon leading to lubricant escapes at the front is called Micro-Plasto-HydroStatic Lubrication (MPHSL) while the term Micro-Plasto-HydroDynamic Lubrication (MPHDL) is used to point out lubricant escapes at the rear of pockets. This terminology will be justified later.

Bech also measured roughness increase where MPH lubrication occurred. The order of magnitude of the peak-to-valley distance in these measurements is $2-5 \mu \mathrm{m}$. According to Bech, this gives an estimate of the film thickness on the plateaus when MPH lubrication takes place.

Such a large difference between the inlet strip thickness $(1.95 \mathrm{~mm})$ and the lubricant film thickness on the plateaus is one of the biggest 


\begin{tabular}{|c|c|c|c|c|c|c|}
\hline $\begin{array}{l}\text { lubricant } \\
\text { viscosity }\end{array}$ & \begin{tabular}{|l|}
$\begin{array}{l}\text { drawing } \\
\text { speed }\end{array}$ \\
\end{tabular} & reduction & die angle & \begin{tabular}{|l|} 
back \\
tension
\end{tabular} & \begin{tabular}{|l|} 
strain hard. \\
exponent
\end{tabular} & $\begin{array}{l}\text { coefficient } \\
\text { of friction }\end{array}$ \\
\hline $\begin{array}{l}\eta=5 \mathrm{cSt} \\
\mathrm{A} 1\end{array}$ & $\begin{array}{l}0.2 \mathrm{~mm} / \mathrm{sec} \\
\mathrm{A} 2\end{array}$ & $\begin{array}{l}\text { IX } \\
10 \% \\
\text { A3 }\end{array}$ & $\begin{array}{ll} & \\
2^{\circ} \\
\mathrm{A} 4\end{array}$ & $\begin{array}{l}r \\
\text { A5, REF } \\
\end{array}$ & $\begin{array}{l}\mathrm{n}=0.08 \\
\mathrm{~A} 6, \mathbf{R E F}\end{array}$ & $\begin{array}{r}\mu=0.025 \\
\text { A7, REF }\end{array}$ \\
\hline $\begin{array}{l}\eta=126 \mathrm{cSt} \\
\mathrm{B} 1, \mathbf{R E F}\end{array}$ & $\begin{array}{l}r \\
0.5 \mathrm{~mm} / \mathrm{sec} \\
\text { B2, REF }\end{array}$ & $\begin{array}{l}15 \% \\
\mathrm{~B} 3 \\
\end{array}$ & $\begin{array}{l}3^{\circ} \\
\text { B4, REF }\end{array}$ & $\begin{array}{l}\text { 51 } \\
62 \mathrm{~N} / \mathrm{mm}^{2} \\
\text { B5 }\end{array}$ & $\begin{array}{l}\mathrm{n}=0.16 \\
\mathrm{~B} 6\end{array}$ & $\begin{array}{l}\mu=0.05 \\
\text { B7 }\end{array}$ \\
\hline $\begin{array}{l}\eta=700 \mathrm{cSt} \\
\mathrm{C} 1\end{array}$ & $\begin{array}{l}5 \mathrm{~mm} / \mathrm{sec} \\
\mathrm{C} 2\end{array}$ & $\begin{array}{l}\text { MX } \\
20 \% \\
\text { C3, REF }\end{array}$ & $\begin{array}{l}5^{\circ} \\
\mathrm{C} 4\end{array}$ & $\begin{array}{l}105 \mathrm{~N} / \mathrm{mm}^{2} \\
\mathrm{C} 5\end{array}$ & $\begin{array}{l}\mathrm{n}=0.21 \\
\mathrm{C} 6\end{array}$ & $\begin{array}{l}\mu=0.28 \\
\mathrm{C} 7\end{array}$ \\
\hline
\end{tabular}

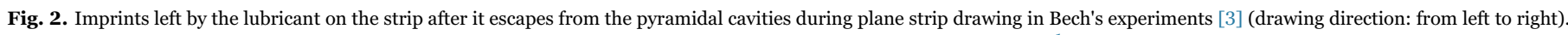
The effect of each parameter is studied one by one and the results are compared to a unique reference test denoted REF. (2-column fitting image).

challenges to tackle. To do so, a multiscale approach is developed. It consists in running successively two numerical models.

The first one, named "full model" deals with a whole strip pulled through rigid tools. A lubricant cavity, present at the strip surface, interacts with the elastoplastic deformation of the strip. During this simulation, the displacements of a rectangular area around the cavity are recorded. They are then used as boundary conditions in a second model named "reduced model". This model focuses on a smaller region around the cavity and is capable of predicting lubricant escapes with a film thickness lower than a micrometre.

These two models are developed with Metafor, an in-house nonlinear FE code [22], under 2D plane strain hypothesis. The models are discussed in the two sections below: the geometry, boundary conditions and the mesh are presented as well as the numerical results.

\subsection{Full model}

\subsubsection{Geometry}

The geometry of the full model is represented in Fig. 3. The aluminium strip is pulled between rigid tools at a constant speed $V_{\mathrm{x}}$. The upper tool is horizontal while the lower one has a slope $\alpha$. A single lubricant pocket is located at the strip surface ahead of the reduction zone. In this way, the cavity reaches the reduction zone once a steady state solid-to-solid contact pressure profile is achieved.

The pyramidal cavity of Bech's experiments is modelled as a triangle surmounted by a thin rectangle. The rectangle height is chosen as $1 \%$ of the triangle depth to minimise the impact of this geometry modification. The reason for this is to achieve a regular mesh - made of quadrangular elements - with a simple transfinite mesher all along the simulation. Otherwise, the mesh would contain at least two triangular or degenerated quadrangular elements at both ends of the cavity which would cause numerical problems in the simulation.

As in Bech's experiments, the slope of the cavity is $10^{\circ}$ and its width is $1 \mathrm{~mm}$ (respectively $\theta$ and $l_{\mathrm{c}}$ in Fig. 3-b). The geometrical dimensions used when modelling the $\mathrm{C} 7$ test conditions are listed in Table 1 .

\subsubsection{Material behaviour}

The aluminium strip elastoplastic behaviour is modelled with the following hardening law:

$\sigma_{Y}=\left(1875.8+21.98 \bar{\varepsilon}^{p l}\right)\left(1-0.042 \exp \left(-13.28 \bar{\varepsilon}^{p l}\right)\right)-1584.2 \mathrm{MPa}$

Numerical parameters are identified on experimental data obtained by Bech with plane strain compression tests.

The fluid is assumed to be Newtonian with a constant viscosity $\eta=35.06 \mathrm{~Pa}$ s which is based on Bech's estimation [3]. A constant bulk modulus $\mathrm{K}=1700 \mathrm{MPa}$ is used to compute the pressure increase in the

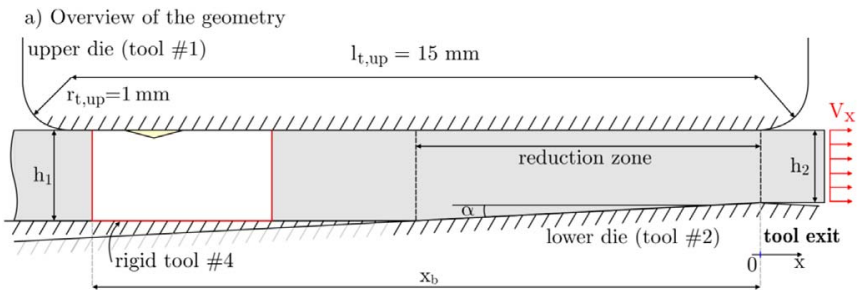

b) Zoom on the rectangular area surrounding the lubricant cavity

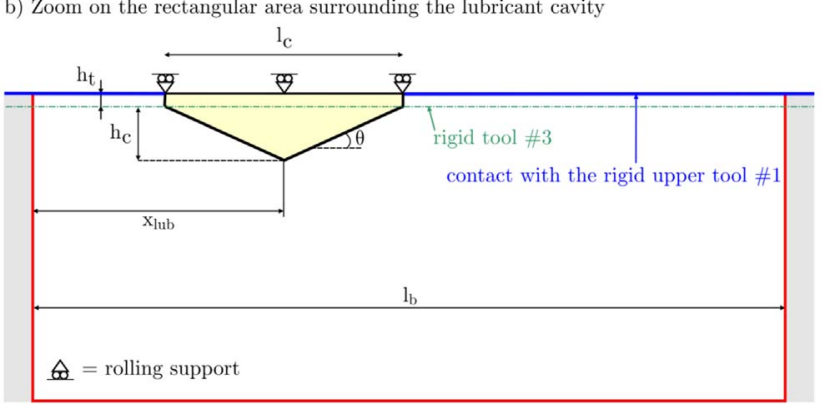

Fig. 3. Geometry of the plane strip drawing model (full model). Rigid tools \#3 and \#4 are numerical artefacts which prevents respectively fluid element distortions and the strip bending due to the tool asymmetry. These artefacts help to manage the complex interactions between the fluid cavity and the elastoplastic deformation of the strip as well as the conditions applied on the fluid upper edge. (2-column fitting image).

lubricant due to the thickness reduction of the strip.

Accounting for such different materials behaviour (aluminium and oil) in the same model is another challenge. Indeed, the dynamic viscosity of the lubricant ( $35.06 \mathrm{~Pa} \mathrm{~s}$ ) is much lower than the shear bulk modulus of aluminium ( $\mathrm{G}=26 \mathrm{GPa}$ ): there is a difference of 9 orders of magnitude between these two values. Extra care must be taken when defining the boundary conditions applied to the model. These are discussed in the next paragraphs.

\subsubsection{Boundary conditions}

The strip motion is induced by prescribed horizontal displacements at a constant speed $V_{x}$ applied on the right edge of the strip (see Fig. 3).

Four rigid contact tools are used in the simulations. The upper one (tool \#1 in Fig. 3) has a horizontal length of $15 \mathrm{~mm}$ and two $1 \mathrm{~mm}-$ radius fillets located at both ends.

The lower tool (\#2) is made of two straight lines having an angle a compared to the horizontal. These lines are linked by a $1 \mathrm{~mm}$-radius fillet located at the tool exit. These two contact tools are representative of the experimental device.

For the purpose of the simulations, two contacts tools were added: one at the bottom of the strip (tool \#4) and another one close to the top 
Table 1

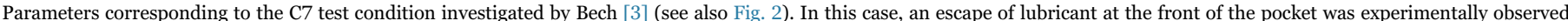
(MPHSL) and is thus expected in the numerical model.

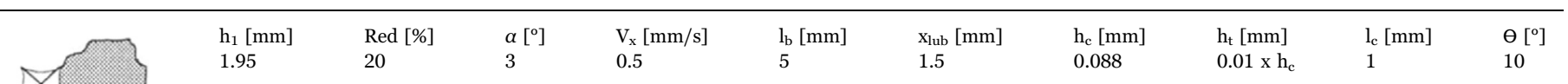

of the strip (tool \#3).

Experimental observations show that the strip thickness reduction induces a shrinkage of the cavity width. This means that the bottom edges of the cavity are moving up and eventually could come into contact with the upper tool. If this happens in the numerical model, this means that, due to the penalty algorithm used to enforce contact conditions that allows - small - interpenetrations, the thickness of the fluid film will become negative! In order to avoid such a physical nonsense, a rigid tool (tool \#3) has been added at a distance $h_{t}$ from the upper tool (tool \#1)) which enforces a minimal fluid thickness of $h_{t}$. This is, of course, a numerical artefact, but $h_{t}$ is always kept very small with respect to the cavity depth and, as will be shown later, the practical choice of $h_{t}$ does not influence much the obtained results.

The horizontal tool at the bottom (\#4) is also an artefact which, this time, prevents the bending of the strip at the entry due to the asymmetry of the tool. By doing that, the complex management of the fluid free surface and its contact with the upper tool is avoided.

Friction conditions are modelled with Coulomb's friction law. During his experiments, Bech used different types of lubricant on the bottom and the top of the strip in order to change the shape of the pressure profile and therefore favouring either lubricant escape at the front or at the rear of the lubricant cavity.

In the simulations, friction coefficient values identified by Bech during his test are used. For the $\mathrm{C} 7$ test condition studied in this section, $\mu_{1}=0.05$ and $\mu_{2}=0.25$ are employed for the upper part and the lower part of the strip respectively.

It is interesting to notice that, when the cavity shrinks, the lower part of the cavity comes into contact with the horizontal tool \#3 and contact is managed as if there was solid-to-solid contact. Therefore, the friction coefficient used there is the same as the one between the upper part of the strip and the upper tool.

The only part where frictionless contact conditions are applied is the lower horizontal tool \#4: it reduces its influence on the process. Indeed, the tool \#4 has an effect on the contact pressure profile between the upper tool and the strip: since the contact length increases. However, these perturbations are confined to the contact entry region and do not affect the area where MPH lubrication occurs.

The interaction of the upper edge of the fluid and the upper tool are not managed by a contact method but rolling support conditions are applied on this edge. Indeed, due to the low viscosity and low compressibility of the fluid material, small gap variations induce instabilities during Newton Raphson iterations at each time step of the simulations. These perturbations are avoided when the vertical displacement is prescribed. There is no adherence conditions applied to the fluid since the flow within the cavity is not our main concern at this stage.

\subsubsection{Spatial and temporal integration}

The time integration is achieved using a Chung-Hulbert implicit dynamic scheme [Chung1993] where the parameters $\alpha_{M}, \alpha_{F}, \beta_{0}, \gamma_{0}$ are respectively set to $-0.97,0.01,0.25$ and 0.5 .

\footnotetext{
${ }^{1}$ Figure reprinted from Wear, Vol 232(2), Bech J, Bay N, Eriksen M., Entrapment and escape of liquid lubricant in metal forming, Page 134-139, Copyright (1999), with permission from Elsevier.
}

In these simulations, four-node elements are used. A selective reduced integration (SRI) method is performed on these elements. The deviatoric part of the stress increment is computed at four Gauss points. The pressure is assumed constant all over the element: it is computed and stored at a single Gauss point at the element centre. This allows us to avoid both volumetric locking as well as hourglass modes [Ponthot1995].

During the rezoning part of the ALE procedure, the hydrostatic pressure field is transferred from the old mesh to the new mesh using a method called Godunov-type update technique based on a finite volume method [Boman2004].

The choices listed above also prevail for the reduced model discussed in the next section.

\subsubsection{C7 test condition: results analysis}

This model allows us to compare the hydrostatic pressure in the lubricant to the contact pressure profile between the upper die and the solid strip material. During the first part of the simulation, the hydrostatic pressure is lower than the solid-to-solid contact at both ends of the cavity pressure explaining that the cavity remains sealed (see Fig. 4-a) and thus there is no fluid flow out of the cavity. Once the front of the pocket is located at $5.2 \mathrm{~mm}$ from the tool exit, the lubricant pressure exceeds the solid-to-solid pressure (see Fig. 4-b). The condition allowing a lubricant flow on the plateau at the front of the pocket is thus fulfilled.

In Fig. 5, a zoom on the mesh ahead of the cavity when this condition is met exhibits a gap between the mesh of the strip and the
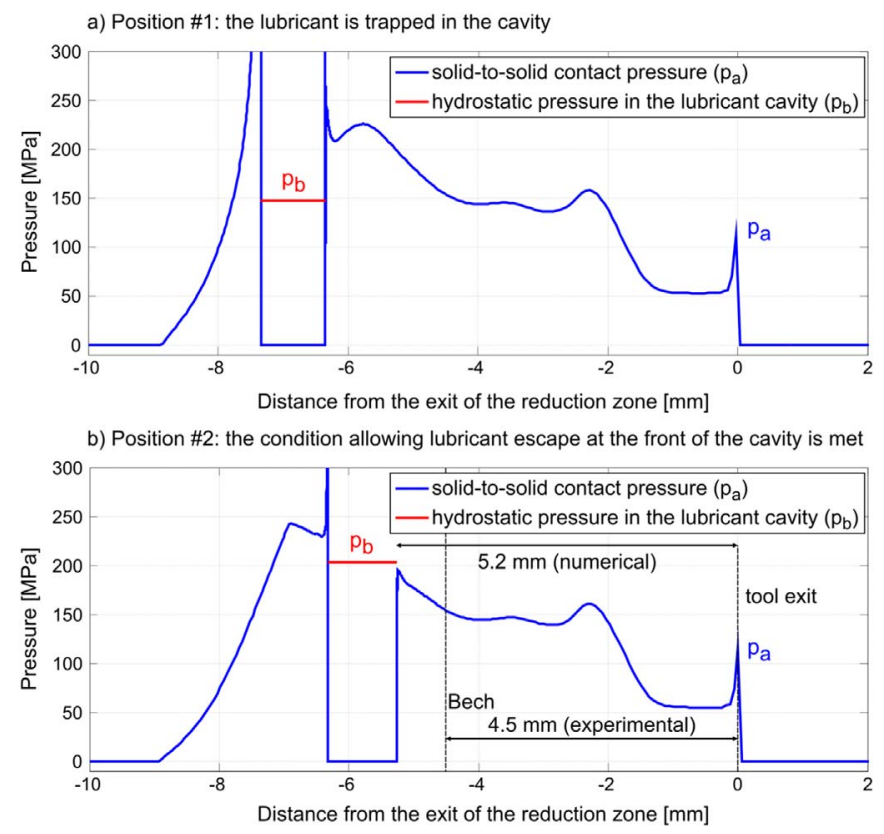

Fig. 4. Comparison of the lubricant hydrostatic pressure $p_{\mathrm{b}}$ to the solid-to-solid contact pressure $p_{\mathrm{a}}$ computed for $\mathrm{C} 7$ test condition. A) Position 1: the lubricant is trapped in the cavity $\left(\mathrm{p}_{\mathrm{b}}<\mathrm{p}_{\mathrm{a}}\right)$. B) Position 2: the condition allowing lubricant escapes $\left(\mathrm{p}_{\mathrm{b}}>\mathrm{p}_{\mathrm{a}}\right)$ is achieved at the front of the cavity $5.2 \mathrm{~mm}$ away from the tool exit. This is close to the measurement of Bech [3] $4.5 \mathrm{~mm}$. (2-column fitting image). 


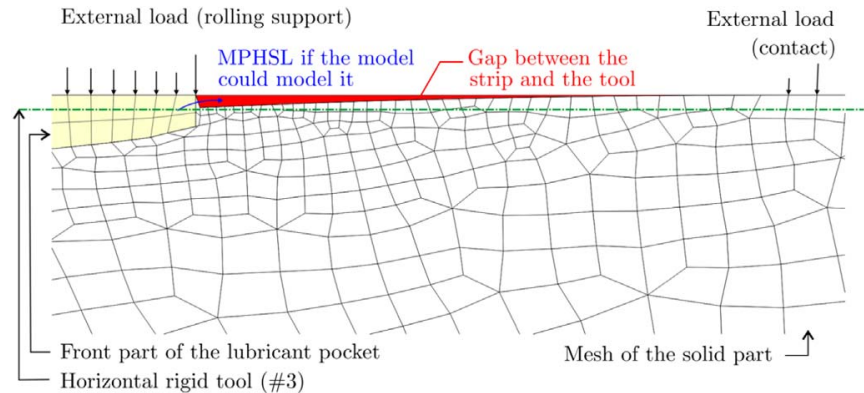

Fig. 5. Zoom on the mesh located on the front part of the lubricant pocket when the condition $p_{\mathrm{b}}>p_{\mathrm{a}}$ is fulfilled. A gap between the strip and the upper tool can be observed (area filled in red). This gap is generated by the lubricant pressure and the elastoplastic deformation of the strip around the cavity which widen the front of the lubricant pocket. (2-column fitting image).

tool \#1. This gap is generated by the lubricant pressure and the strip deformation around the lubricant pocket which widens the right edges of the cavity. The strip deformations are themselves affected by the contact conditions, the strip thickness reduction, the pulling speed, etc.

It is clear that there is no pressure transmitted to the upper tool on the edge of the cavity in Fig. 5 but the length of this zone is so small that it is negligible with respect to the scale of Fig. 4-b, which explains why it is not perceptible in this Figure.

Also, in the configuration represented in Fig. 5, tool \#3 has no effect whereas it is required for the configuration presented in Fig. 4-a when the solid-to-solid contact pressure is larger than the fluid pressure.

To illustrate that behaviour, Fig. 6 compares the initial configuration and final shape of the cavity after the cavity has reached the reduction zone. We can clearly see in that figure that, after deformation, the rear part is closed while the left and right edges are pushed to the right therefore inducing a lubricant cavity escape at the front.

This is due to the large difference in the frictional behaviour at the top and bottom of the strip. In the present case, friction is larger at the bottom. Sliding is thus more constrained, generating a strain gradient through the thickness which induces the pocket shape presented in the Fig. 6 favouring lubricant escape at the front.

The model described above is not realistic beyond the moment when the condition $p_{\mathrm{b}}>p_{\mathrm{a}}$ is met because it does not allow the fluid to escape from the pocket and fill the gap. To take this phenomenon into account a finer model must be used. It is described in the following section.

\subsection{Reduced model}

The aim of the microscopic model is to account for lubricant escapes from the main cavity. To do so, two thin meshed pipes with an initial thickness close to zero are added at both ends of the cavity (as

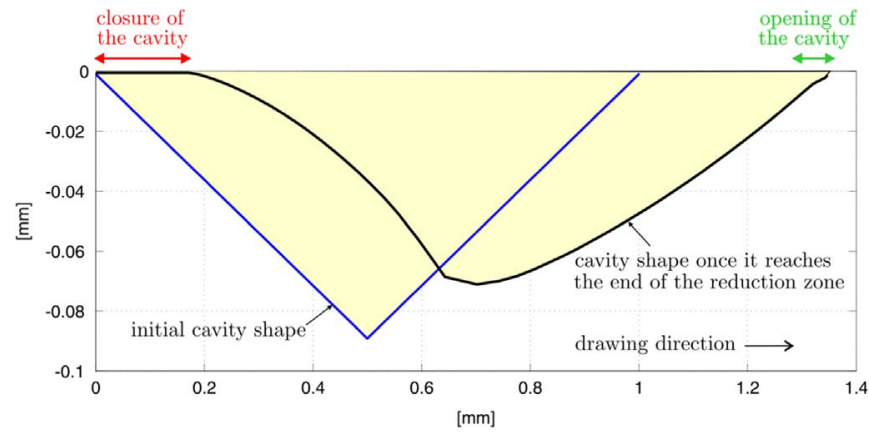

Fig. 6. Comparison of the final shape of the cavity once it is drawn through the reduction zone and the initial triangular shape for $\mathrm{C} 7$ tests condition. The final cavity shape is such that the lubricant flow occurs at the front while the rear of the cavity is closed. (2-column fitting image).

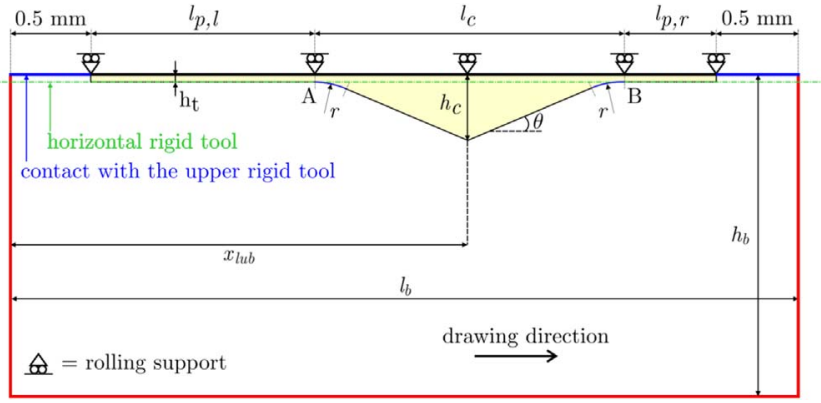

Fig. 7. Initial geometry of the reduced model used to observe lubricant escape at the rear or at the front of the pocket in the REF test condition from Bech's experiments. (2column fitting image).

illustrated in Fig. 7). Thanks to the use of the Arbitrary Lagrangian Eulerian (ALE) formalism, the lubricant may escape from the triangular cavity to fill the pipes and to lubricate the plateaus.

The model is used to reproduce REF test condition from Bech's experiments (see Fig. 2). The test parameters are the same as in the C7 test condition studied above. The only differences concern the strip thickness reduction which is $21.5 \%$ in the present case and the friction level on top and bottom of the strip which are respectively $\mu_{1}=0.05$ and $\mu_{2}=0.025$. The REF test condition is chosen here since it experimentally highlights both MPHDL and MPHSL lubrication flows.

Thus, another simulation has been conducted with the full model discussed in previous section. Then, these results have been applied as boundary conditions in the reduced model as explained in the following paragraphs.

\subsubsection{Geometry}

The geometry is represented in Fig. 7. It consists of a rectangular strip at the top of which is located the fluid domain. This domain is made of a rectangular cavity linked to two very thin rectangular areas (called pipes). The transition between these pipes and the cavity is achieved by two fillets having a radius $r$.

The geometrical dimensions used to model the REF test conditions are listed in Table 2. The initial length of both pipes is determined from Bech's measurements of the lubricant escapes at the front and the rear of the cavity. The pipe thickness is chosen as $0.3 \mu \mathrm{m}$ : an order of magnitude smaller than the peak-to-valley measurement on the plateaus where relubrication occurs.

Due to the very small thickness used for the pipes, the resulting mesh for the whole model is really too big to solve the problem on a personal computer. Therefore we only consider a small rectangular region of the strip around the pocket. The strip thickness is $1.95 \mathrm{~mm}$ as in Bech's experiments. Its length is $1 \mathrm{~mm}$ larger than the fluid domain: $0.5 \mathrm{~mm}$ in excess on each side.

\subsubsection{Material}

The strip elastoplastic material as well as the viscous fluid behaviour are modelled with the material laws as in the full model discussed above.

\subsubsection{Boundary conditions}

2.3.3.1. Prescribed displacements. The length of the mesh $\left(l_{\mathrm{b}}=5 \mathrm{~mm}\right)$ is smaller than the contact zone $(9.5 \mathrm{~mm}$ in the REF test case see Fig. 4). To be representative of the real process, displacements are prescribed on the lower edge and the vertical edges of the mesh. These displacements are approximated from a prior simulation using the first full-scale model (without ALE pipes) described in the previous section. In this way, the effects computed by the microscopic model are representative of the strip drawing process even though the whole strip is not considered. 
Table 2

Geometrical parameters used to model the REF test condition investigated by Bech [3]. In this case, the lubricant escapes both backward (MPHDL) and forward (MPHSL).

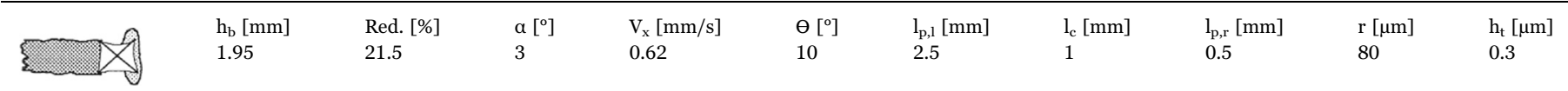

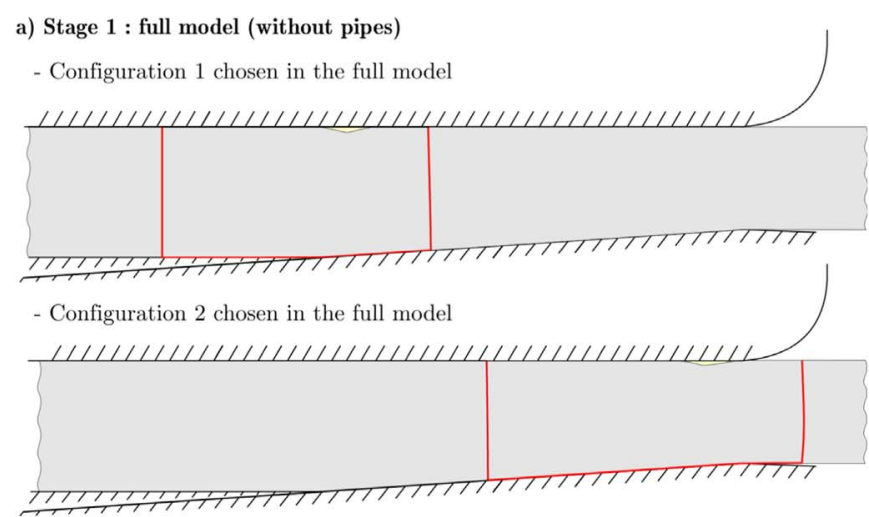

b) Stage $2:$ reduced model (with pipes)

- Phase 1 : prescribed displacements applied on the initial geometry to obtain the shape of configuration 1 chosen in the macroscopic model

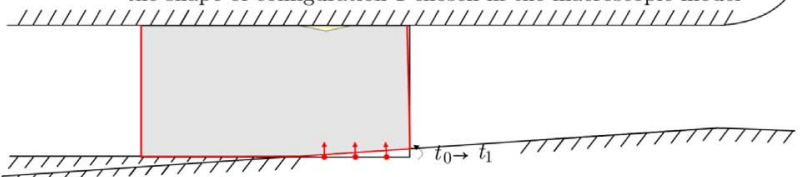

- Phase 2 : prescribed displacements applied on the edges of the microscopic model (except from the upper edge)
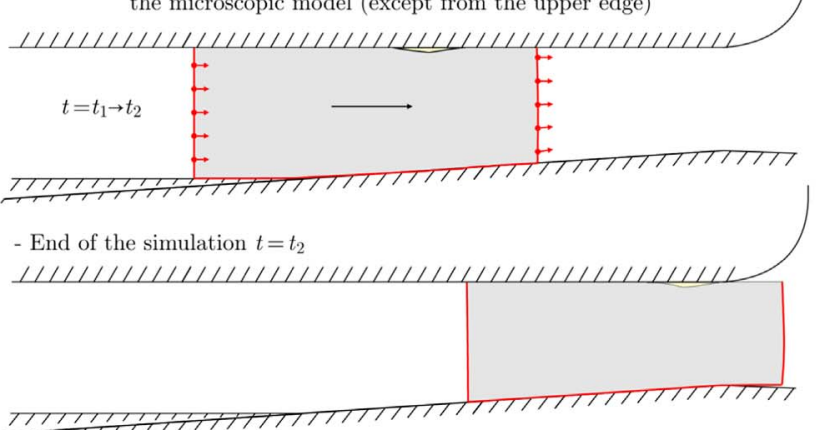

Fig. 8. Schematic view of the methodology used to apply prescribed displacements on the edges of the reduced model. A) Selection, from the full-model results, of the initial and final configuration to be used in the reduced model. B) Application of the prescribed displacements in two phases. Phase1: displacement applied to match the shape of configuration 1 chosen in the full model. Phase 2: prescribed displacements linearly interpolating the successive positions of the edges computed in the full model. (2-column fitting image).

Practically speaking when analysing the full (macroscopic) model results, two configurations noted 1 and 2 are selected when the lubricant cavity is at the beginning of the contact zone and close to the exit (see Fig. 8). They correspond to the initial and final configuration considered in the microscopic simulation.

In the reduced model, to go from the initial geometry to configuration 1, prescribed displacements linearly interpolating these two stages are applied between $t_{0}$ and $t_{1}$ (see Fig. 8-b - Phase 1). Then prescribed displacements interpolating the positions recorded in the macroscopic model at each time step are used (see Fig. 8-b Phase 2).

2.3.3.2. Contact management. The upper edge of the strip is in contact with an additional rigid tool identical to the one used in the macroscopic model. As in the macroscopic model, there is a rigid horizontal tool, at a distance $h_{t}$ from the upper tool which enforces a minimal thickness of the pipe preventing mesh distortions.

2.3.3.3. Boundary conditions applied on the upper part of the fluid. For the same reasons as in the full model, the vertical motion of the fluid free surface is prevented by rolling support conditions. However, in this case, the fluid adhesion to the tool must be taken into account since lubricant escapes at the rear are affected by the hydrodynamic effect in the converging gap between the tool and the cavity.

Initially, adhesion conditions $\left(\mathrm{V}_{\mathrm{x}, \mathrm{f}}=0\right.$ - the upper tool is fixed) are applied on the nodes at the top of the triangular cavity while the nodes in the pipes are free to move horizontally (see Fig. 9-a. Indeed, the lubricant initially located in the pipes is a numerical trick which allows fluid motion initiation on the plateaus.

Adhesion conditions are automatically updated at given times during the simulation depending on the local lubricant film thickness in the pipes. Once the local thickness is larger than twice $h_{t}$, adhesion is enforced. However, when the local thickness falls below this threshold this condition is deactivated and the nodes are again free to move horizontally. In this way the amount of oil drawn on the plateaus once the pocket is closed is reduced.

In the simulation presented here, the automatic update occurs each time the strip moves $0.25 \mathrm{~mm}$ in the contact zone.

\subsubsection{REF test condition: results analysis}

In the REF test condition, Bech [3] observed lubricant escape at the rear and at the front of the main lubricant cavity. For this case, as we shall see, the numerical model also predicts two openings of the cavity at the rear and at the front, therefore generating micro-cavities on the plateaus.

a) Initial configuration :

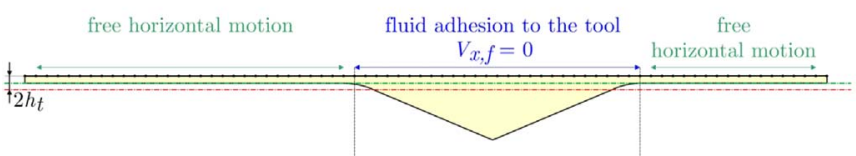

b) Opening of the rear of the pocket :

Extension of the adhesion condition - $V_{x, f}=0$ - on the nodes located where the fluid film thickness is at least two times thicker than the initial value $: h(x)>2 h_{t}$

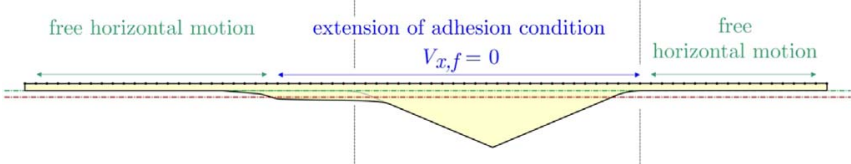

c) Pocket closure :

Deactivation of adhesion condition on nodes located above those from the fluid-solid interface which come into contact with the rigid tool (see green line) which prevent pipes from flattening completely

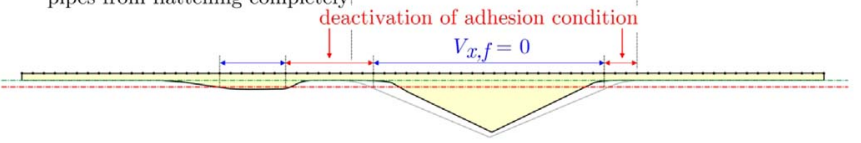

Fig. 9. Schematic representation of the evolution of boundary conditions applied on the upper part of the fluid domain in the reduced model. (2-column fitting image). 
a) Initial configuration

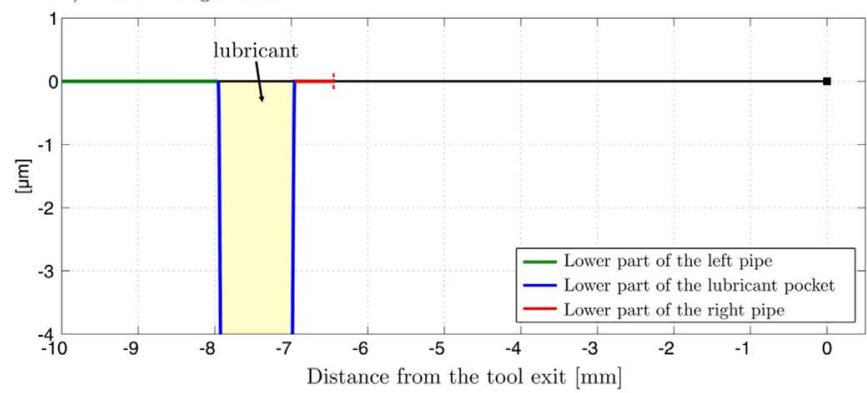

b) Opening of the rear of the pocket (MPHDL)

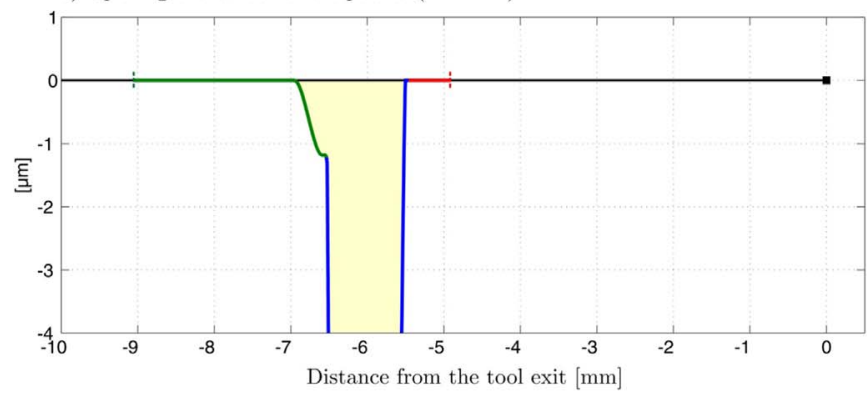

c) Closing of the rear of the pocket

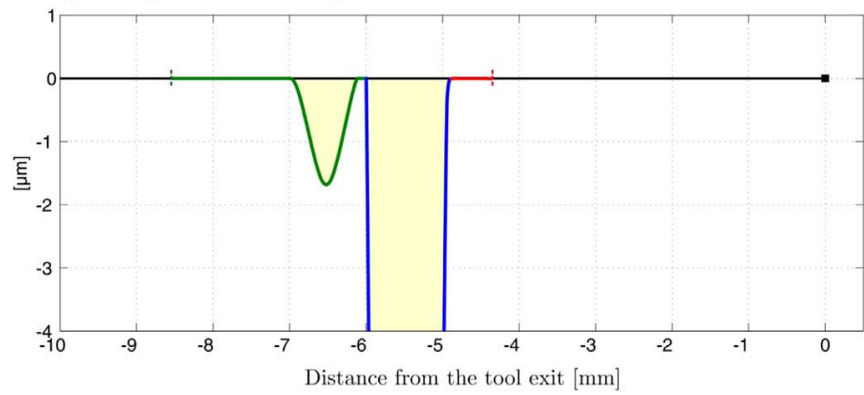

Fig. 10. Evolution of the shape of the lower part of the lubricant pocket and the pipes for successive positions in the contact zone: REF test condition (part 1/3). The vertical scale has been magnified by a factor of 1000 . (2-column fitting image).

The evolution of the shape of the upper part of the lubricant cavity and the lower part of the pipes during strip drawing is depicted in Figs. 10-12. Initially, the two pipes are in contact with the horizontal tool enforcing a minimal film thickness $h_{t}$ (see Fig. 10-a).

In Fig. 10-b the rear part of the cavity opens allowing some lubricant to flow on the plateaus at the rear. Then, the cavity closes generating a micro-cavity on the plateaus. This cavity remains stationary due to adhesion condition (see Fig. 10-c, d and e) until it reaches the end of the pipe (see Fig. 10-f) which is a limitation of the present model.

In the meantime, the triangular cavity opens at the front (see Fig. 11-d) generating a micro-cavity (see Fig. 11-e). This micro-cavity then resorbs due to the pressure induced by the strip deformation in this area and the permanent link with the main cavity. This microcavity then completely disappears (see Fig. 11-f).

Towards the end of the process, both the rear part and the front part of the main cavity opens (see Fig. 11-g and h respectively). This induces a second micro-cavity on the plateaus at the rear while the front part of the main cavity remains wide open until the end of the contact zone is reached. At the end of the simulation, the opening at the front $(6 \mu \mathrm{m})$ is much larger than the depth of the micro-cavities at the rear $(3 \mu \mathrm{m})$.

2.3.4.1. Cavity closure. The evolution of the shape of the lubricant pocket and the pipe discussed above and depicted in Figs. 10-12 shows that the rear and front parts of the lubricant pocket close once some d) Opening of the pocket front (MPHSL)
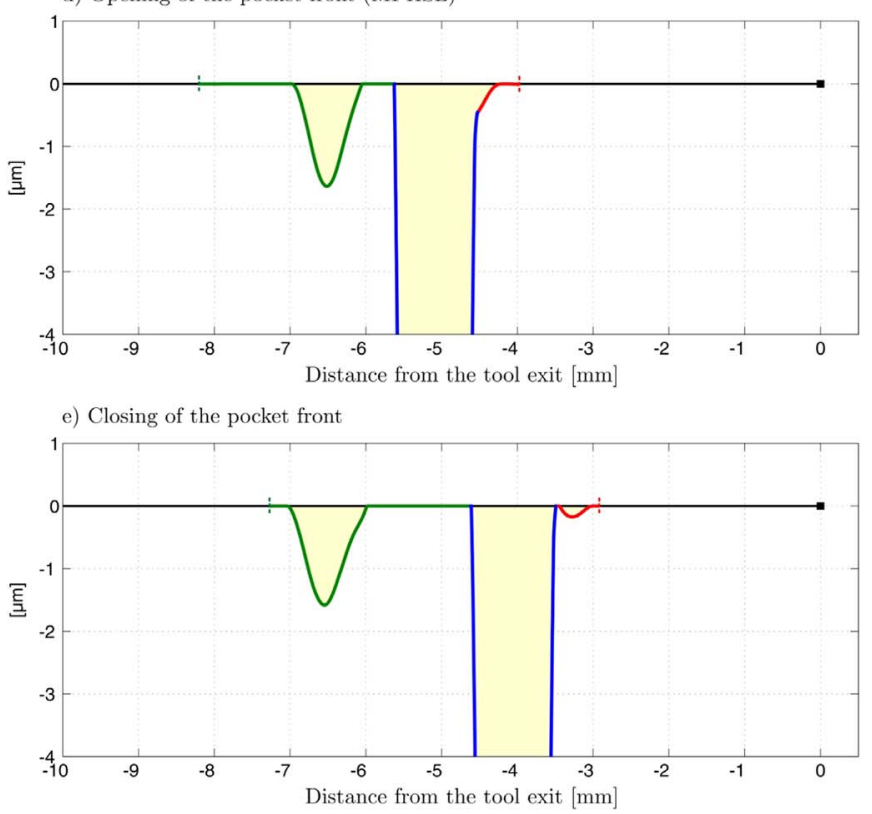

f) The micro-cavity generated at the rear reaches the end of the left pipe resorption de la micro-cavity located at the front

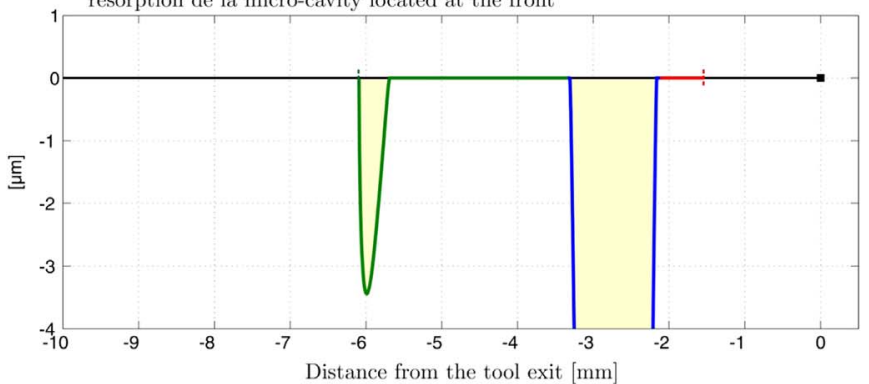

Fig. 11. Evolution of the shape of the lower part of the lubricant pocket and the pipes for successive positions in the contact zone : REF test condition (part 2/3). The vertical scale has been magnified by a factor of 1000 . (2-column fitting image).

lubricant has escaped (see for instance Figs. 10-c, 11-e and 12-i). This observation seems to be consistent with experiments.

Indeed, two consecutive snapshots of a video recorded by Bech [3] during one of his tests, represented in Fig. 13, show that the rear of the pocket closes once lubricant has escaped backward and a solid-to-solid contact zone between the tool and the strip appears. The fluid is still present on the plateaus, but the adhesion of the fluid to the upper tool tends to pull the fluid away from the main cavity. According to these experimental observations, the pocket closure predicted by the numerical model seems to have a physical meaning.

2.3.4.2. Influence of the initial lubricant film thickness on the plateaus. Since it can be considered as a pure artifact, the effect of the initial pipe thickness $\left(\mathrm{h}_{\mathrm{t}}\right)$ is investigated. Simulations are conducted with $h_{t}=0.3-0.4$ and $0.5 \mu \mathrm{m}$. This section shows that the value of $h_{t}$ has minimal influence on the simulation results proving the legitimacy of the current approach.

Fig. 14 represents the vertical displacement of the geometrical point situated at the rear of the cavity (see point a, at the transition between the fillet and the left pipe, in Fig. 7) for the three values of $h_{t}$ mentioned above. The three resulting curves overlap nearly perfectly. In all cases, there are two openings of the back of the pocket in accordance with the analysis carried out previously. The first pocket opening starts $7.1 \mathrm{~mm}$ ahead of the tool exit while the second one begins at $3.2 \mathrm{~mm}$ from the 


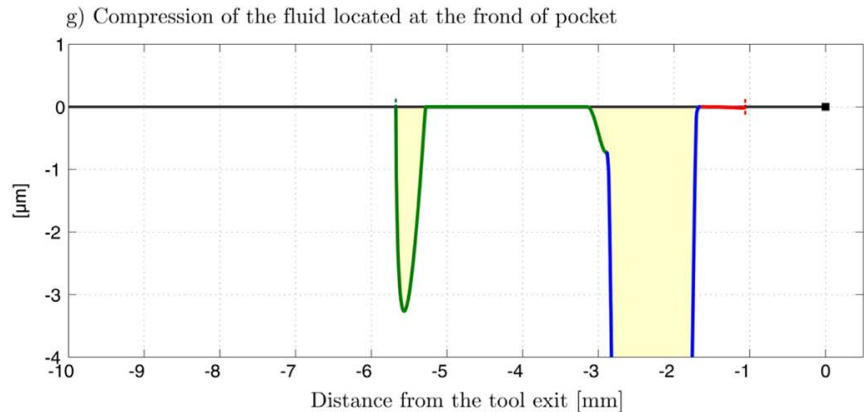

h) 2nd opening of the rear (MPHDL) and the front (MPHSL) of the pocket

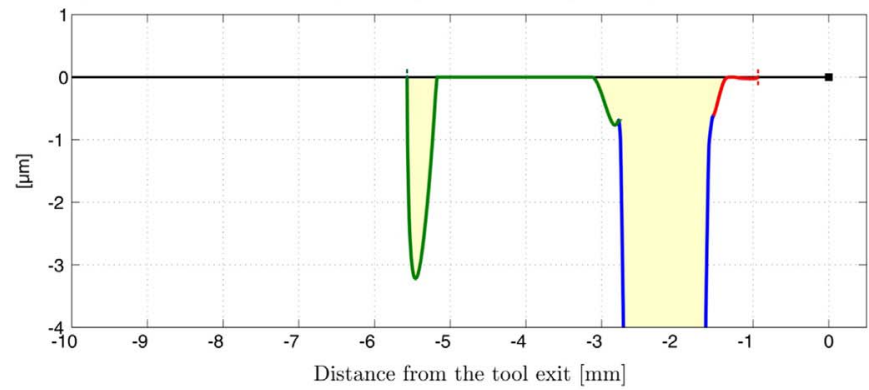

i) Closing of the rear of the pocket - opening of the pocket front (MPHSL)

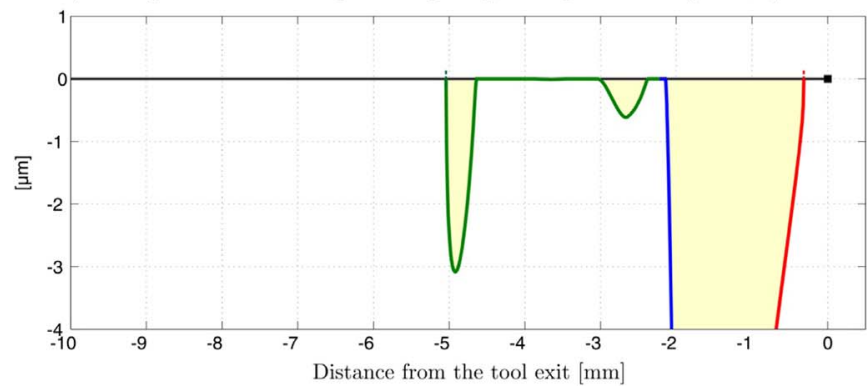

Fig. 12. Evolution of the shape of the lower part of the lubricant pocket and the pipes for successive positions in the contact zone: REF test condition (part 3/3). The vertical scale has been magnified by a factor of 1000 . (2-column fitting image).

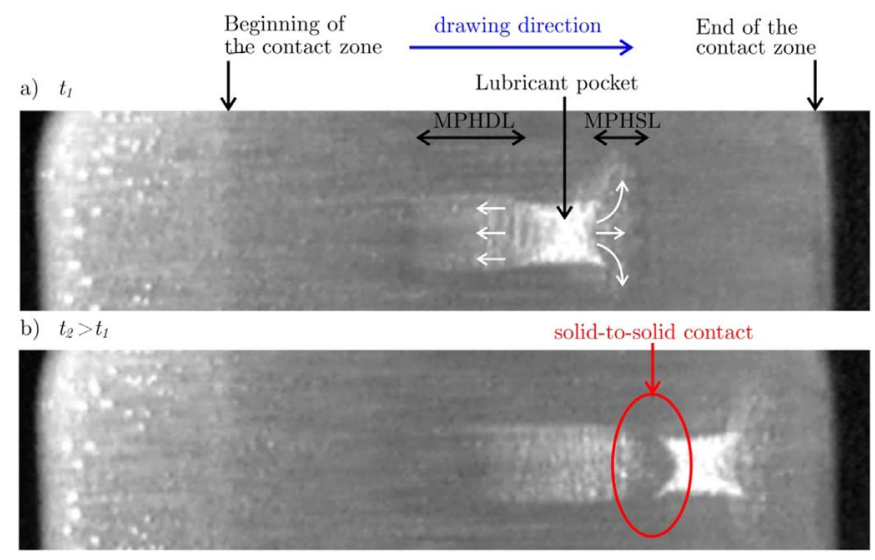

Fig. 13. Snapshots taken from a video recorded by Bech during one of his experiments. These pictures show the rear of the pocket closes once MPHDL has occurred. (2-column fitting image).

exit. The maximum displacement is more important for the first opening $(1.32 \mu \mathrm{m})$ than for the second one $(0.81 \mu \mathrm{m})$.

The vertical displacement of the front of the pocket is shown in Fig. 15. Again, the three curves obtained with different values of $h_{t}$ used perfectly overlap. Two cavity openings take place. They respectively start at 4.9 and $1.6 \mathrm{~mm}$ of the exit of the contact area. This time, the maximum displacement is larger for the second opening $(6.6 \mu \mathrm{m})$ compared to the first one $(0.9 \mu \mathrm{m})$.

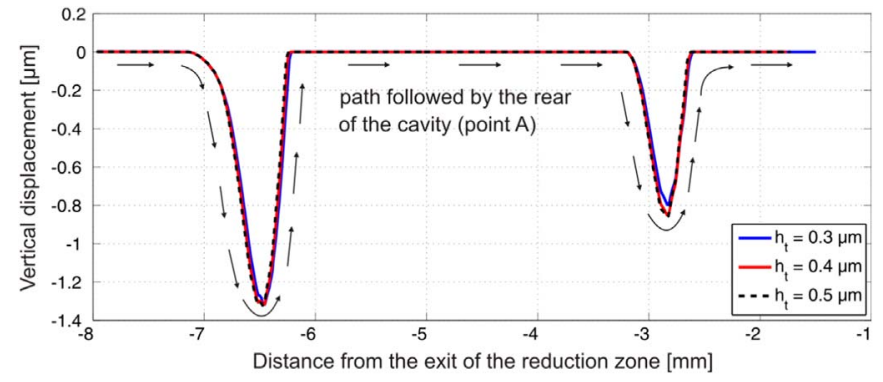

Fig. 14. Vertical displacement of the rear part of the cavity (see point A in Fig. 7), while the strip is pulled through the reduction zone, for three initial pipes thickness $\left(h_{t}\right)$ values. The arrows refer to direction of the motion. (2-column fitting image).

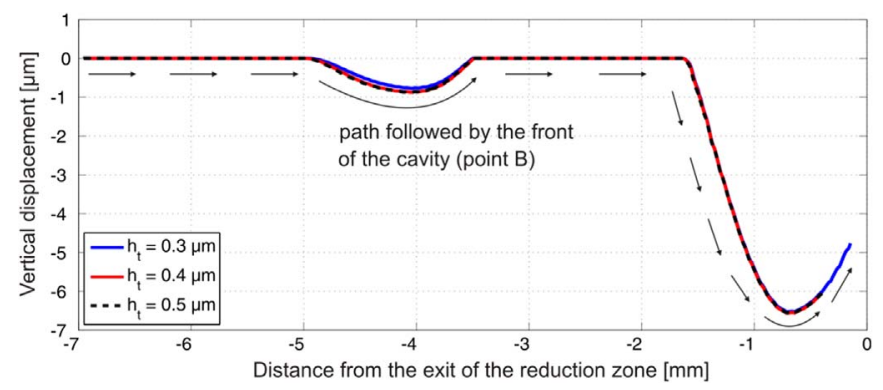

Fig. 15. Vertical displacement of the front part of the cavity (see point B in Fig. 7), while the strip is pulled through the reduction zone, for three initial pipes thickness $\left(h_{t}\right)$ values. The arrows refer to direction of the motion. (2-column).

The value of $h_{t}$ does not influence the cavity openings but it has an influence on the amount of lubricant dragged on the plateaus: the larger the initial film thickness, the larger the pipe volume variation.

The evolution of the volume brought to the left pipe as the strip is drawn through the tool is represented in Fig. 16. The trends are similar for the three values of $h_{t}$ investigated here. First, there is a significant volume change when the rear of the pocket opens. Then, between 4 and $7.5 \mathrm{~s}$, while the rear of the cavity is closed, the volume increases linearly: the larger $h_{t}$, the larger the slope. This is due to the permanent link between the micro-cavity generated on the plateaus and the main cavity. Indeed, the adhesion condition applied on the fluid in the micro-cavity brings more lubricant from the main cavity into the micro-cavity as the strip is pulled through the tool.

When $t=8 \mathrm{~s}$, a reduction in volume is observed. This is due to the second opening of the pocket which draws some fluid out of the pipe. At $t=9 \mathrm{~s}$, there is a large volume variation due to the closure of the rear of the pocket which again brings some lubricant on the plateaus. Finally, the volume increases linearly for the same reasons as explained above.

The results discussed above show the model is able to reproduce plane strip drawing experiments highlighting microscopic lubricant flows. The obtained results demonstrate the model is able to predict the Micro-Plasto-HydroDynamic lubrication at the rear of the pocket as

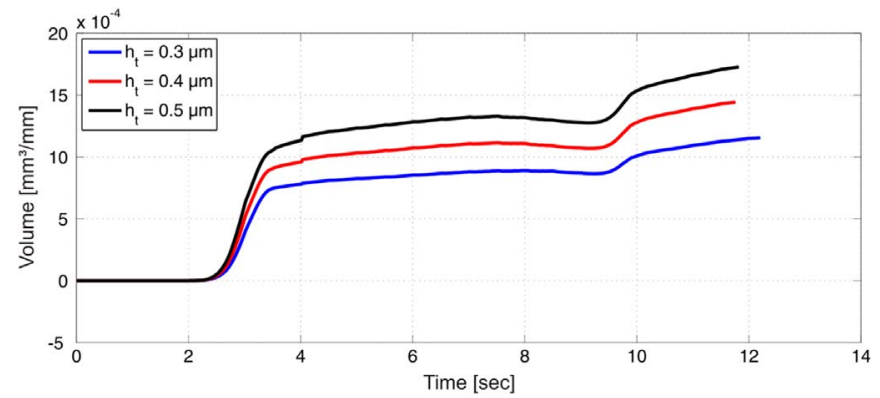

Fig. 16. Volume brought to the left pipe when modelling REF test condition from Bech's experiments for three initial pipe thickness values. The larger $h_{t}$, the larger the volume. (2-column fitting image). 
well as the Micro-Plasto-Hydrostatic flow at the front of the cavity.

Although this model is much more representative than those described in the literature, it still presents, like any model, different limitations:

- Numerical simulations described here are conducted in 2D assuming plane strain conditions. Therefore, the cavity has a constant triangular section along the width of the strip whereas the actual shape is pyramidal. The present model therefore neglects $3 \mathrm{D}$ effects such as flows in the transverse direction (see A1. - B5 - C5 - C6 - B7 $\mathrm{C} 7$ in Fig. 2). However, the extent of the lubricant flow in the transverse direction is generally much smaller than the one in the drawing direction.

- The piezo-viscous behaviour of the lubricant is not taken into account. To consider this, a precise characterisation of the lubricant is needed. Since we do not have accurate data for the lubricant used by Bech [3] during his tests, this dependence is not accounted for in the present work.

- The same properties are used for the fluid in the main cavity and the micro-cavity generated on the plateaus. Nevertheless, it seems unlikely that a thin lubricant layer of a few microns thickness has identical properties to those of thicker oil films.

- The micro-cavities formed on the pipes are permanently connected to the main cavity through the pipes. Therefore, a fluid motion between the main cavity and micro-cavities on the plateaus is possible while the main cavity is closed in theory.

- Pipes used in the model have a finite length fixed a priori. Therefore, in order to predict the mark of the lubricant left by the fluid flowing on the plateaus, initial pipe lengths have to be sufficiently large.

- The equations solved in the model are based on the assumption of continuous medium. Given the thickness of the pipes used in the simulations $(0.3 \mu \mathrm{m})$ and the microscopic size of lubricant film thickness, this assumption is somewhat undermined. Indeed, these dimensions approach the size of the metal grains and the molecules constituting the lubricant.

- The present model is not able to represent the roughness increase observed by Bech in his tests. When a full film separates a tool and a metal sheet deforming plastically, the metal grains located close to the surface of the sheet can slide relative to each other which generate an increase in the strip roughness. This effect, called roughening, has an influence on the lubricant flow on the plateaus and is not taken into account in the present model.

\section{Sensitivity analysis}

A sensitivity analysis is conducted with the reduced model described above. The influence of three parameters is studied: the lower tool slope, the strip thickness reduction and the drawing velocity. For each of these tests, the vertical displacements of the rear and the front of the main cavity are presented. Moreover, the shape of the lower part of the pipes at the rear and the front of the cavity are compared to the lubricant mark measured on the strip after drawing.

\subsection{Influence of the lower tool slope}

Three numerical simulations are carried out with different values of lower tool slope of $2^{\circ}, 3^{\circ}$ and $5^{\circ}$. Strip reduction thickness and drawing velocity are kept constant for these tests. They are respectively $21.5 \%$ and $0.62 \mathrm{~mm} / \mathrm{s}$.

\subsubsection{Experimental results}

Experimental measurements in Fig. 17 show that the longest mark let by the lubricant on the strip, at the rear of the pocket, is obtained for a slope of $3^{\circ}$ while the shortest corresponds to a slope of $5^{\circ}$.

At the pocket front, lubricant marks are observed next to the corner of the cavities. These marks become wider as the slope of the lower tool

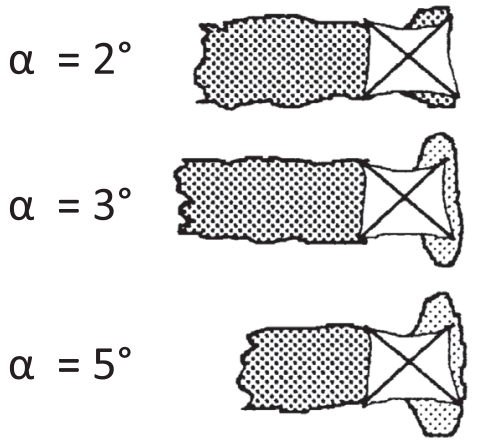

Fig. 17. Experimental measurements of the marks let by the lubricant around the pyramidal cavity after drawing for three lower tool slope values a (nb: the drawing direction is from the left to the right).(single fitting image).

increases.

\subsubsection{Numerical results}

Fig. 20 shows the lower part of the pipes and the pocket once the front part of the right pipe reaches tool exit. At the rear of the pocket, a small cavity is formed for a tool slope of $2^{\circ}$. There are two for the REF test condition (slope $=3^{\circ}$ ) and only one of larger volume for a die angle of $5^{\circ}$.

The vertical displacement of the rear part of the pocket is depicted in Fig. 18. The pocket opens twice for a slope of $3^{\circ}$ (at $19 \%$ and $65 \%$ of the contact length) and only once when the die angle is $5^{\circ}$ (at $44 \%$ of the contact length). Nevertheless the opening is wider in the latter case. This is the reason why the volume increase in the left pipe is larger for a slope of $5^{\circ}$ (Fig. 19).

One of the micro-cavity on the plateau reaches the end of the pipe when the die angle is $3^{\circ}$. However, since the triangular cavity opens later for the steeper case (44\% instead of $19 \%$ of the contact length in the REF case), the lubricant micro-cavity does not reach the end of the pipe. Thus, the numerical model predicts a shorter lubricant mark at the rear which is consistent with experimental results.

Fig. 20 also shows that the fluid flows at the front of the pocket. The front cavity opens twice for $\alpha=2^{\circ}$ and $\alpha=3^{\circ}$ and only once for $\alpha=5^{\circ}$. The larger the slope is, the larger is the opening (see also Fig. 19). These observations are consistent with Bech's experimental results.

\subsection{Strip thickness reduction}

The strip thickness reduction effect is investigated with a constant velocity of $0.62 \mathrm{~mm} / \mathrm{s}$ and a die angle of $3^{\circ}$. Three thickness reduction values are tested: $10 \%, 15 \%$ and $21.5 \%$.

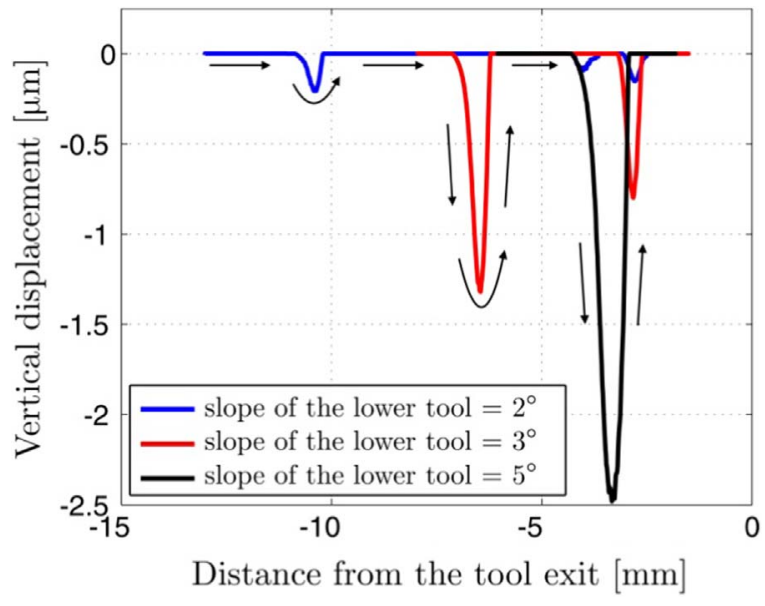

Fig. 18. Vertical displacement of the rear part of the pocket as the strip is pulled through the die. The arrows refer to direction of the motion. (single fitting image). 


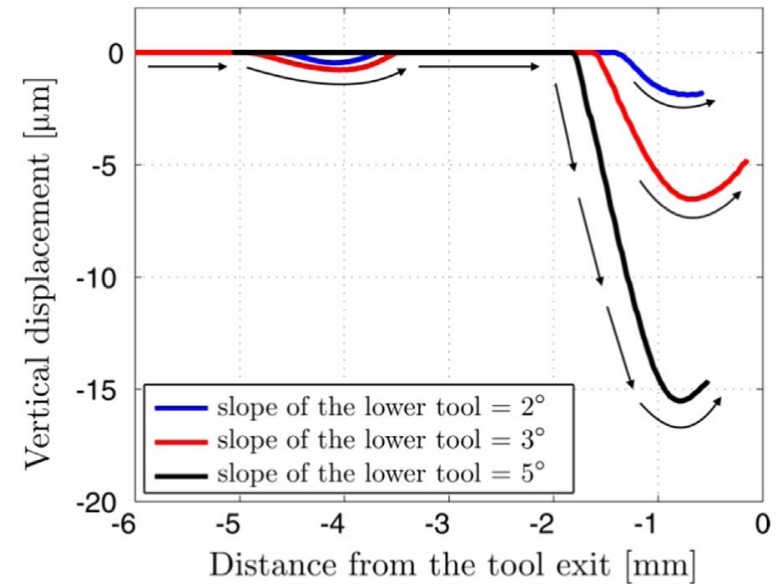

Fig. 19. Vertical displacement of the front part of the pocket as the strip is pulled through the die. The arrows refer to direction of the motion. (single fitting image).

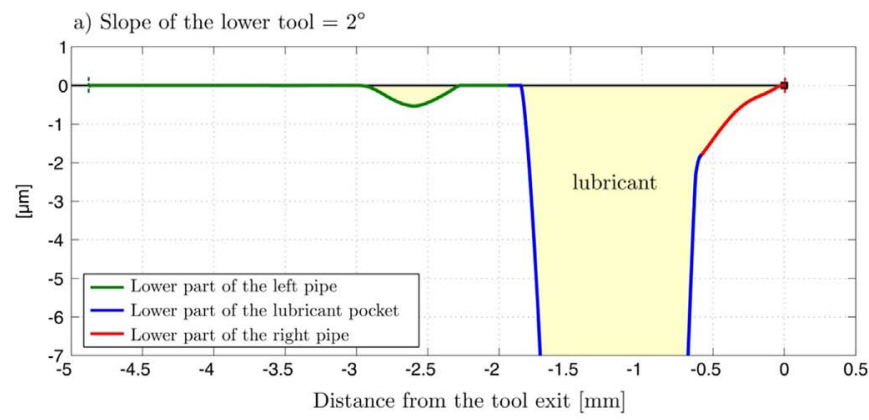

b) Slope of the lower tool $=3^{\circ}(\mathbf{R E F})$

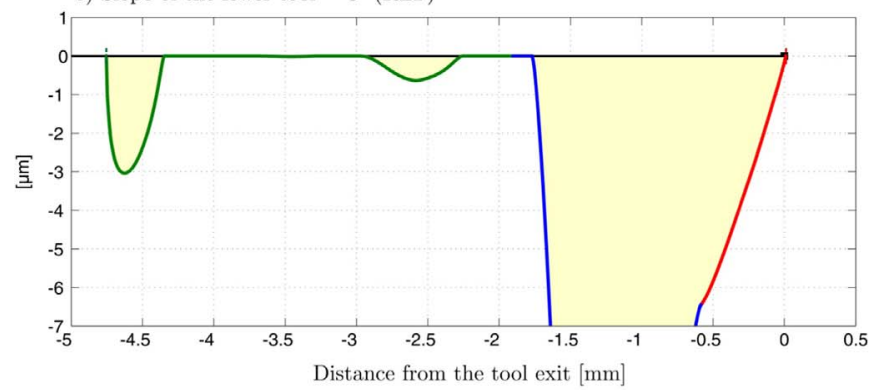

c) Slope of the lower tool $=5^{\circ}$

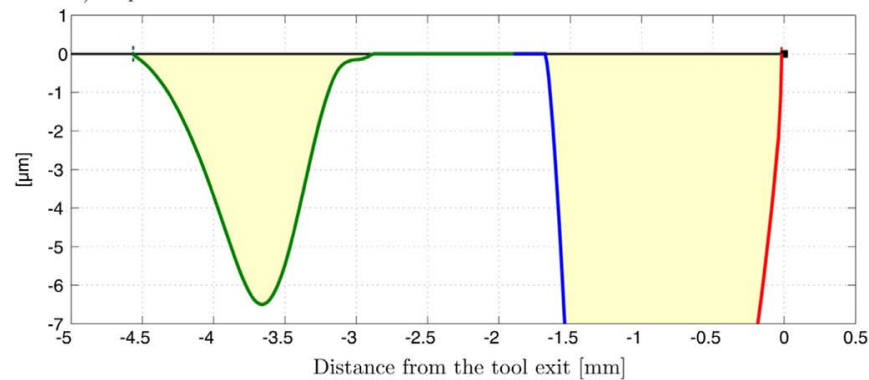

Fig. 20. Shape of the lower part of the pipes and the pocket once the front part of the right pipe reaches tool exit for three values of the lower tool slope. (2-column fitting image).

\subsubsection{Experimental results}

The marks let by lubricant on the strip around the cavity at the end of the drawing experiments for three strip thickness reduction level are represented in Fig. 21. These marks become larger both at the rear and at the front as strip thickness reduction increases.

\subsubsection{Numerical results}

Fig. 24 shows that there is no lubricant escapes for a strip thickness red. $=10 \%$

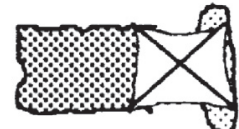

red. $=15 \%$

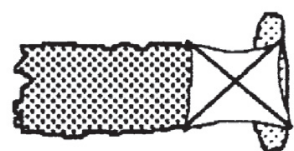

red. $=21.5 \%$

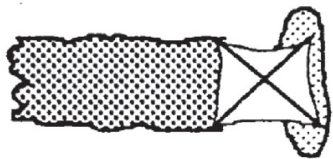

Fig. 21. Experimental measurements of the marks let by the lubricant around the pyramidal cavity after drawing for three strip thickness reduction values (nb: the drawing direction is from the left to the right). (single fitting image).

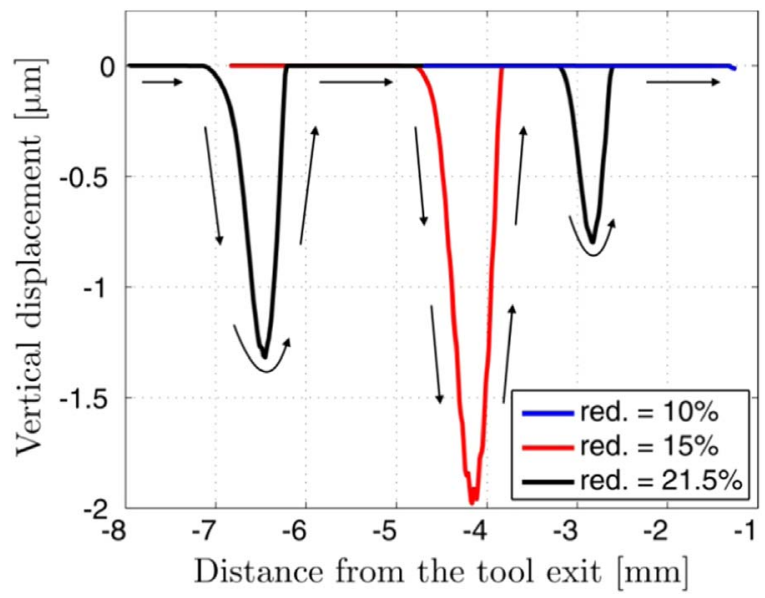

Fig. 22. Vertical displacement of the rear part of the pocket as the strip is pulled through the die. The arrows refer to direction of the motion(single fitting image).

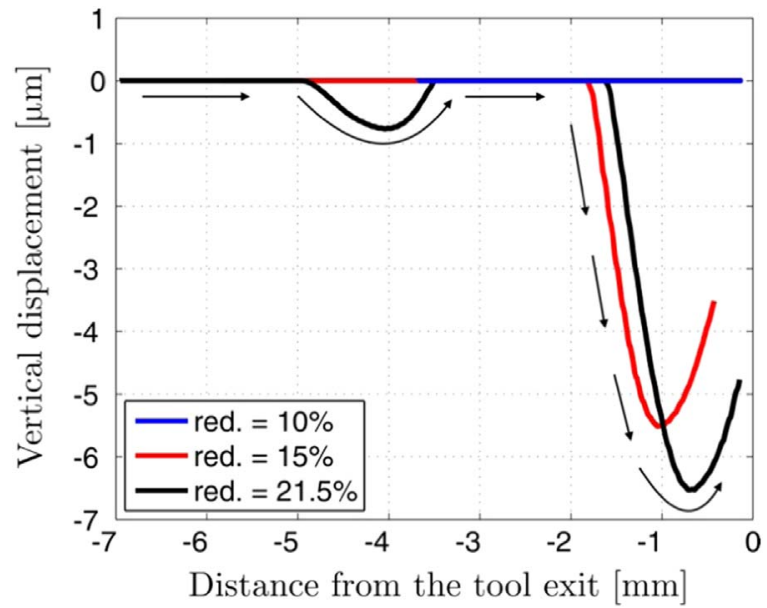

Fig. 23. Vertical displacement of the front part of the pocket as the strip is pulled through the die. The arrows refer to direction of the motion(single fitting image)

reduction of $10 \%$. This is not consistent with experimental data since Bech observed lubricant marks in this case. After investigation, it appeared the actual strip thickness reduction level used in that test is $11.8 \%$ and not $10 \%$. This might explain the difference. Nevertheless, this numerical result is important since it shows that there exists a threshold under which no lubricant flow occurs.

For a strip reduction of $15 \%$, the rear of the pocket opens once while it opens twice for a reduction of $21.5 \%$. Nevertheless pocket opening is wider in the first case leading to a larger volume increase of 
a) Strip thickness reduction $=10 \%$

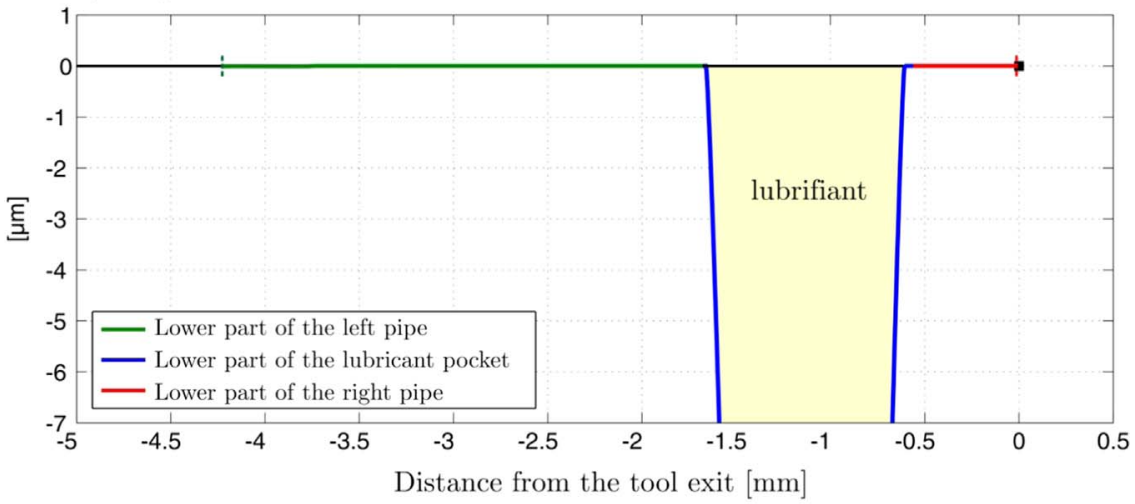

b) Strip thickness reduction $=15 \%$

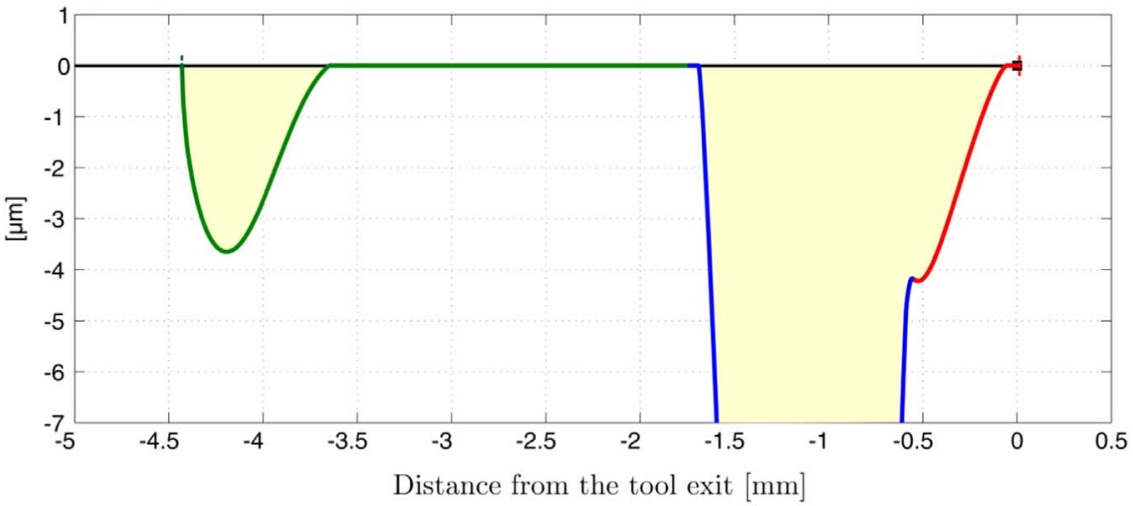

c) Strip thickness reduction $=21.5 \%(\mathbf{R E F})$

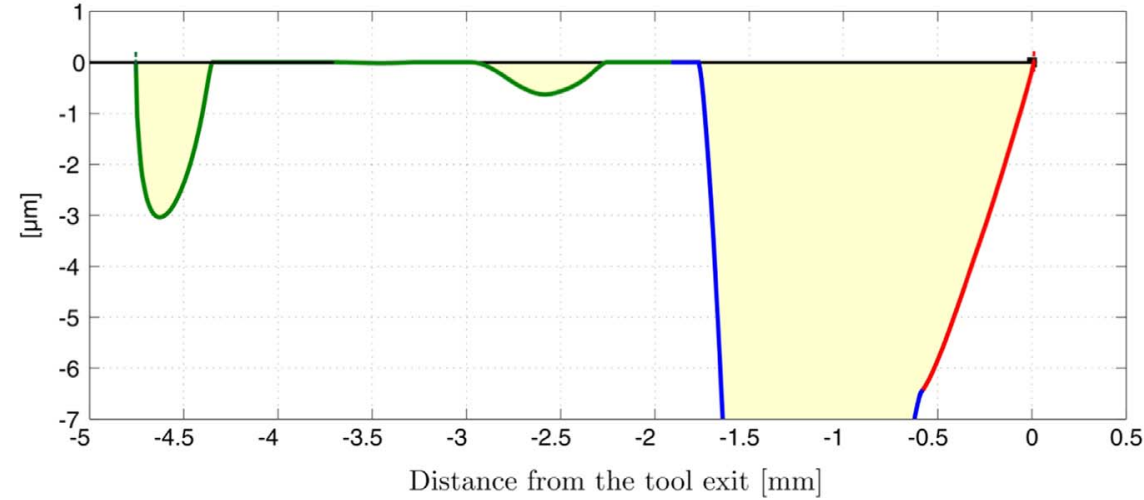

Fig. 24. Shape of the lower part of the pipes and the pocket once the front part of the right pipe reaches tool exit for three strip thickness reduction levels. (2-column fitting image).

$$
\begin{aligned}
& V=0.2 \mathrm{~mm} / \mathrm{s} \\
& V=0.5 \mathrm{~mm} / \mathrm{s} \\
& V=5.0 \mathrm{~mm} / \mathrm{s}
\end{aligned}
$$

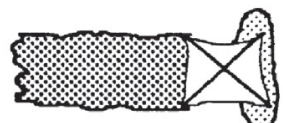

Fig. 25. Experimental measurements of the marks let by the lubricant around the pyramidal cavity after drawing for three strip drawing speed levels (nb: the drawing direction is from the left to the right). (single fitting image).

the pipe located at the rear of the pocket (see Figs. 22 and 24).

The lubricant flow on the plateau reaches the end of the rear pipe for a reduction of $15 \%$ and $21.5 \%$. As in the experimental observations, the larger the strip thickness reduction, the larger the flow length at the rear.

The front of the cavity opens once for a reduction of $15 \%$ and twice for the largest reduction (see Fig. 23). Moreover, the maximal displacement is larger for a strip thickness reduction of $21.5 \%$. This observation is consistent with the experimental results showing a wider lubricant print at the front as the reduction level increases.

\subsection{Drawing velocity}

The drawing velocity effect is investigated in the numerical model with a strip thickness reduction of $21.5 \%$ and a die angle $\alpha$ of $3^{\circ}$. Three velocity values are tested: $0.62 \mathrm{~mm} / \mathrm{s}, 2 \mathrm{~mm} / \mathrm{s}$ and $5 \mathrm{~mm} / \mathrm{s}$. The velocity of $0.2 \mathrm{~mm} / \mathrm{s}$ - tested by Bech - is not used here to avoid a too large computational time. 


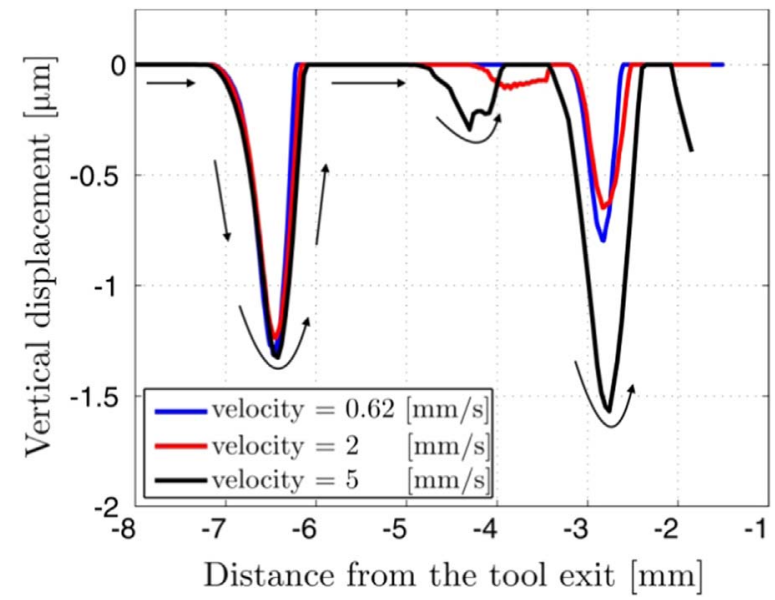

Fig. 26. Vertical displacement of the rear part of the pocket as the strip is pulled through the die. The arrows refer to direction of the motion. (single fitting image).

\subsubsection{Experimental results}

Experimental results in Fig. 25 indicate a larger lubricant mark at the rear as the drawing velocity increases. At the front, the opposite happens: the marks become shorter.

\subsubsection{Numerical results}

The rear of the pocket opens twice for the lowest velocity, three times when $V_{\mathrm{x}}=2 \mathrm{~mm} / \mathrm{s}$ and four times for the largest velocity $\left(V_{\mathrm{x}}\right.$ $=5 \mathrm{~mm} / \mathrm{s}$ ). This is due to the hydrodynamic effect in the converging gap at the rear of the cavity.

Paradoxically, the volume of the left pipe at the end of the process at the higher speed is not much larger than the one corresponding to the lower velocity (see Fig. 28). Indeed, at a lower velocity, lubricant has more time to escape from the cavity. For instance, the first opening of the pocket is identical in the three cases (see Fig. 26). Therefore, the pocket remains open for a longer period of time when the velocity is low leading to a larger volume variation of the left pipe.

The micro-cavities on the plateaus reach the end of the rear pipe for $\mathrm{V}=0.2$ and $0.5 \mathrm{~mm} / \mathrm{s}$ whereas it does not for $\mathrm{V}=5 \mathrm{~mm} / \mathrm{s}$. This is not in agreement with experimental measurements.

On the other hand, at the front, the maximal vertical displacement decreases as the drawing velocity increases (see Figs. 27 and 29) which is consistent with the experimental observations. This is due to the noslip condition between the fluid and the upper tool which prevents lubricant escapes at the front as the drawing velocity increases.

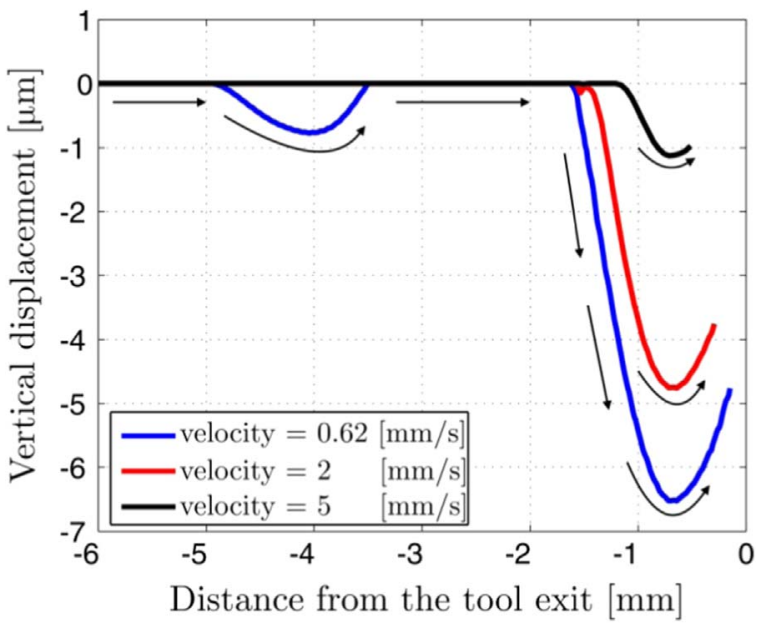

Fig. 27. Vertical displacement of the front part of the pocket as the strip is pulled through the die. The arrows refer to direction of the motion. (single fitting image).

\section{Conclusion}

This paper presents a multi-scale finite element model capable of modelling the occurrence of MPH lubrication. This phenomenon consists in lubricant flows from isolated surface cavities and has been observed in various sheet metal forming processes. For instance, several authors such as Bech witnessed lubricant being squeezed out from lubricant oil pockets at the front and the rear during plane strip drawing.

Modelling MPH lubrication requires a numerical tool capable of performing fluid-structure interaction simulations. The simulations presented here are conducted with the in-house finite element code Metafor. In these simulations, the lubricant is assumed to be Newtonian and modelled with the Norton-Hoff material law. The solid material, on the other hand, is elastoplastic and modelled with a classical isotropic hardening material law.

The difficulties linked to large deformations of low viscosity fluid elements are overcome thanks to the use of the Arbitrary Lagrangian Eulerian formalism, which allows us to uncouple the motion of the mesh and the material. Therefore a good quality mesh is achieved throughout the whole fluid domain in all the simulations presented in this paper.

One of the biggest challenges to tackle when modelling MPH lubrication is the microscopic thickness of the flow. To overcome this difficulty, a multi-scale approach is developed. It implies running successively two numerical simulations. The first one models the interaction between the elastoplastic deformation of a strip and the deformation of a triangular cavity filled with lubricant. Displacements recorded in this simulation are then used as boundary conditions in a second model focusing on a smaller area around the lubricant cavity. In this model, two very thin fluid area called pipes are added at both ends of the cavity. Thanks to the use of the ALE formalism, the lubricant can inflate the pipes and flow on the plateaus.

The model is used to reproduce a test condition encountered by Bech for which he observed a lubricant flow at the rear and at the front of the cavity. The numerical model predicts several openings of the cavity at the rear and at the front allowing lubricant to escape and generating micro-cavities on the plateaus. This proves that the model is able to predict the Micro-Plasto-HydroDynamic lubrication at the rear of the pocket as well as the Micro-Plasto-HydroStatic flow at the front.

The numbers of openings of the main cavity at the rear and at the front as well as the displacement amplitudes are insensitive to the initial pipe thickness $h_{t}$ which justifies the present approach. However, this parameter affects the amount of lubricant flowing on the plateaus when MPHDL and MPHSL occur. Indeed, there is a direct link between these micro-cavities and the main cavity even when the main cavity is closed in theory. Therefore, the adhesion condition applied on the fluid in the micro-cavity tends to bring more lubricant to the plateaus while the main cavity is closed which is a limitation of the model.

The present model is the first of his kind able to accurately predict the onset of MPH lubrication flow and to give an estimate of the local lubricant film thickness.

The effect of three key parameters of the process has been investigated: the lower tool slope, the strip thickness reduction level and the drawing speed. Most of the numerical results are in good agreement with the measurements conducted by Bech.

The larger the drawing speed the larger the number of openings at the rear of the cavity. This was expected and it is due to the hydrodynamic effect in the converging gap at the rear of the cavity.

The study of the strip thickness reduction effect shows there is a threshold under which MPH lubrication does not occur. It is an important feature. Indeed, a larger strip thickness reduction normally leads to larger friction forces in the process. However, if the MPH lubrication is triggered, the friction forces might be reduced due to lubricant escapes on the plateaus. This local friction coefficient decrease with strip thickness reduction has already been observed in 


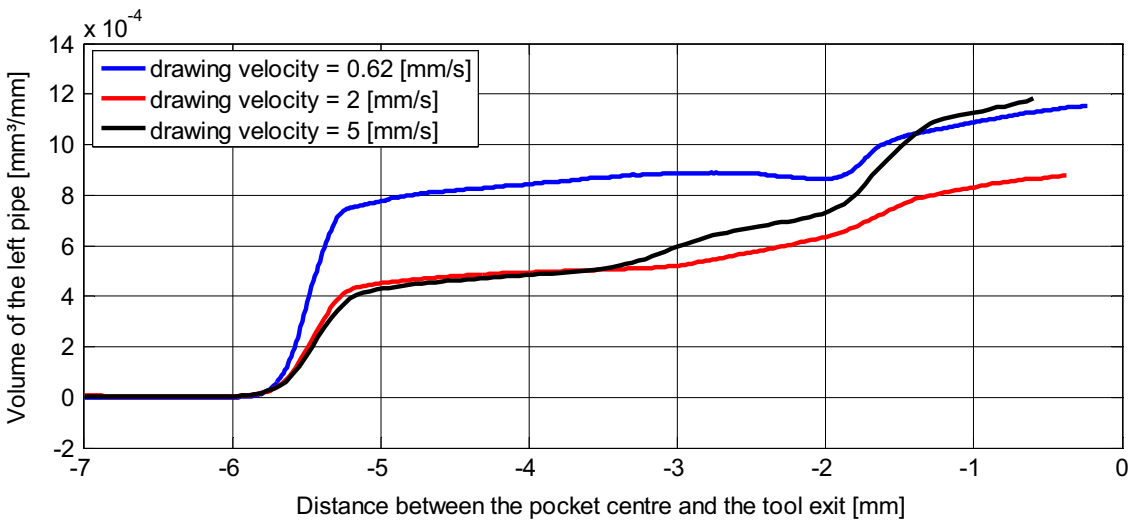

Fig. 28. Volume increase in the left pipe (rear of the pocket) as the strip is pulled through the die. (2-column fitting image).

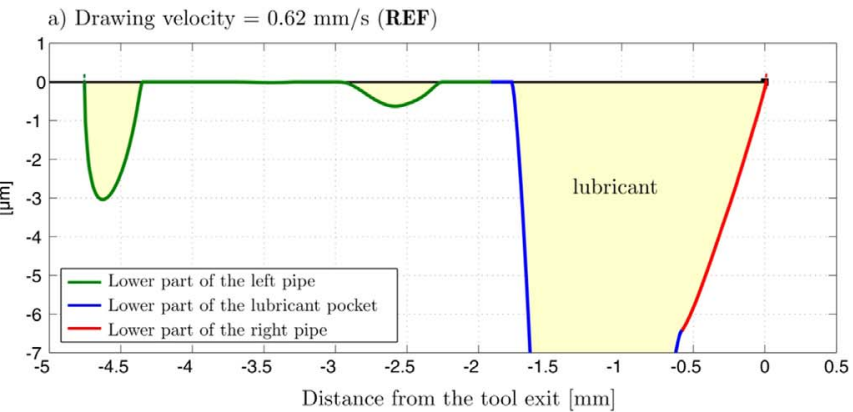

b) Drawing velocity $=2 \mathrm{~mm} / \mathrm{s}$
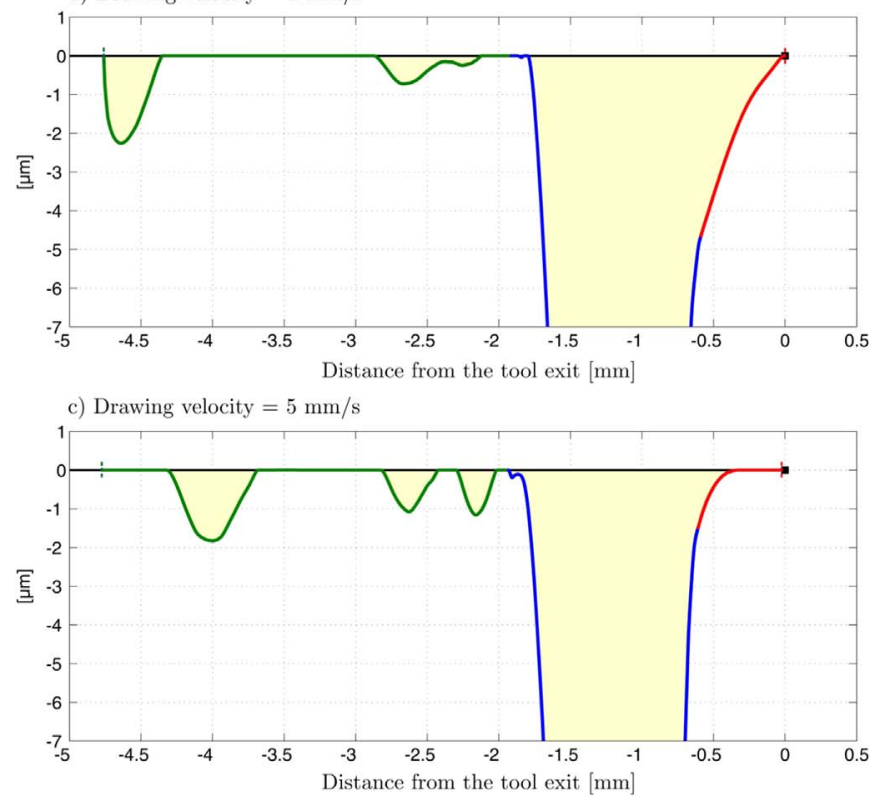

Fig. 29. Shape of the lower part of the pipes and the pocket once the front part of the right pipe reaches tool exit for three drawing speed levels. (2-column fitting image).

other processes like cold rolling of high-strength steel (HSS) [8]. Mastering MPH lubrication to be able to reduce friction when needed is a challenge which needs to be addressed to ensure the feasibility of some sheet metal forming processes like cold rolling of HSS where friction forces are important.

Some actions are now undertaken in order to include MPH lubrication effect in cold rolling. This work will be presented in subsequent publications.

For all the tests presented in the present paper, the lubricant escapes occur in several stages. This is a new feature of MPH flow. This could be confirmed or contradicted by conducting experimental film thickness measurements. These would indeed be helpful to determine whether lubricant film on the plateaus is continuous or not. Such measurements could be performed using ultrasonic sensors. This technique has indeed been used in the field of tribology to measure continuous thin lubricant layers in a number of studies, such as those looking into journal bearings and mechanical seals [23-26].

The MPH model could be improved by including a more complex behaviour law to model the lubricant. To do so, more experimental data are necessary. Ideally, lubricant viscosity and bulk modulus pressure dependence should be known. The effect of such parameters could influence the MPHDL onset at the rear of the pocket.

The numerical simulations currently require a long computational time: about 10 days. This is due to small mesh elements in the thin lubricant layers at both ends of the main cavity. These thin lubricant layers could be replaced by contact elements able to determine a local friction coefficient upon the integration of an average Reynolds equation. The latter would take into account the influence of asperities on the flow. Elements of this type have been used by Boman and Ponthot [27] in FE simulations of cold rolling when the hydrodynamic regime occurs in the roll bite. Several challenges will be faced when using such kind of elements. The first one concerns the transition between the solid - solid contact (managed by a conventional type law Coulomb) to the lubricated contact once the conditions required for the appearance of MPHSL or MPHDL are met. Another difficulty will be to determine the initial lubricant film thickness required to integrate Reynolds equation in order to compute local shear stress. Apart from a smaller computational time, these elements would provide a way to predict the length of the contact area affected by MPH flows.

\section{Acknowledgements}

Yves Carretta gratefully thanks ArcelorMittal, FRIA (Fonds pour la formation à la Recherche dans l'Industrie et dans l'Agriculture), the Walloon Region and the European Social Fund for financial support through grant First-International: convention $\mathrm{n}^{\circ} 1217863$.

\section{References}

[1] T. Mizuno, M. Okamoto, Effects of lubricant viscosity at pressure and sliding velocity on lubricating conditions in the compression-friction test on sheet metals, J Lubr Technol 104 (1982) 53-59.

[2] Azushima A, Tsubouchi M, Kudo H. Direct observation of lubricant behaviour under the Micro-PHL at the interface between workpiece and die. Proceedings 3rd International Conference of Technology in Plasticity; 1:551-556; 1990.

[3] J. Bech, N. Bay, M. Eriksen, Entrapment and escape of liquid lubricant in metal forming, Wear 232 (2) (1999) 134-139.

[4] C. Sørensen, J. Bech, J. Andreasen, N. Bay, U. Engel, T. Neudecker, A basic study of the influence of surface topography on mechanisms of liquid lubrication in metal forming, CIRP Ann - Manuf Technol 48 (1) (1999) 203-208.

[5] I. Shimizu, J. Andreasen, J. Bech, N. Bay, Influence of workpiece surface topography on the mechanisms of liquid lubrication in strip drawing, J Tribol 123 (2) (2001) 290-294.

[6] Azushima A Direct observation of contact behaviour to interpret the pressure 
dependence of the coefficient of friction in sheet metal forming. Ann. CIRP; 47/ 1:479-482.

[7] R. Ahmed, M. Sutcliffe, An experimental investigation of surface pit evolution during cold-rolling or drawing of stainless steel strip. ASME, J Tribol 123 (1) (2001) $1-7$

[8] M. Laugier, R. Boman, N. Legrand, J.-P. Ponthot, M. Tornicelli, J. Bech, Y. Carretta, Micro-plasto-hydrodynamic lubrication: a fundamental mechanism in cold rolling, Adv Mater Res: Tribol Manuf Process Join Plast Deform (2014) $228-241$.

[9] S.-W. Lo, T.-C. Horng, Lubricant permeation from micro oil pits under intimate contact condition, J Tribol 121 (1999) 633-638.

[10] S.-W. Lo, W.R.D. Wilson, A theoretical model of micro-pool lubrication in metal forming, J Tribol 121 (4) (1999) 731-738.

[11] M.P.F. Sutcliffe, H.R. Le, R. Ahmed, Modeling of micro-pit evolution in rolling or strip-drawing, J Tribol 123 (4) (2000) 791-798.

[12] I. Shimizu, P. Martins, N. Bay, J. Andreasen, J. Bech, Influences of lubricant pocket geometry and working conditions upon micro-lubrication mechanisms in upsetting and strip drawing, Int J Surf Sci Eng 4 (1) (2010) 42-54.

[13] Hubert C, Bay N, Christiansen P, Deltombe R, Dubar L, Dubar M, Dubois A. Numerical simulation of lubrication mechanisms at mesoscopic scale. AIP conference proceedings; 2011 1353(1):1729-1734.

[14] L. Dubar, C. Hubert, P. Christiansen, N. Bay, A. Dubois, Analysis of fluid lubrication mechanisms in metal forming at mesoscopic scale, CIRP Ann - Manuf Technol 61 (1) (2012) 271-274.

[15] R. Deltombe, A. Belotserkovets, L. Dubar, Numerical hybrid fluid structure coupling: application to mixed lubrication in metal forming, Adv Mater Res 966967 (2014) 377-385.

[16] M. Bigerelle, J. Nianga, D. Najjar, A. Iost, C. Hubert, K. Kubiak, Roughness signature of tribological contact calculated by a new method of peaks curvature radius estimation on fractal surfaces, Tribol Int 65 (2013) 235-247.
[17] C. Hubert, K.J. Kubiak, M. Bigerelle, L. Dubar, Identification of local lubrication regimes on textured surfaces by 3D roughness curvature radius, Adv Mater Res 966-967 (2014) 120-125.

[18] C. Hubert, K.J. Kubiak, M. Bigerelle, A. Dubois, L. Dubar, Identification of lubrication regime on textured surfaces by multi-scale decomposition, Tribol Int 82 (2015) 375-386.

[19] M. Steitz, P. Stein, P. Groche, Influence of hammer-peened surface textures on friction behaviour, Tribol Lett 58 (2) (2015) 1-8.

[20] D. Aktürk, P. Liu, J. Cao, Q.J. Wang, Z.C. Xia, R. Talwar, D. Grzina, M. Merklein, Friction anisotropy of Aluminum 6111-T4 sheet with flat and laser-textured D2 tooling, Tribol Int 81 (2015) 333-340.

[21] A. Godi, J. Grønbæk, L. De Chiffre, Off-line testing of multifunctional surfaces for metal forming applications, CIRP J Manuf Sci Technol 11 (2015) 28-35.

[22] METAFOR. A large strain finite element software. University of Liège (LTASMN2L), 〈http://metafor.ltas.ulg.ac.be〉 [accessed 1.07.2016]; 2016.

[23] Dwyer-Joyce RS, Drinkwater BW, Donohoe CJ. The measurement of lubricant-film thickness using ultrasound. Proceedings of the Royal Society A; 459:957-976; 2003.

[24] R.S. Dwyer-Joyce, P. Harper, B.W. Drinkwater, A method for the measurement of hydrodynamic oil films using ultrasonic reflection, Tribol Lett 17 (2) (2004) 337-348.

[25] T. Reddyhoff, R.S. Dwyer-Joyce, P. Harper, A new approach for the measurement of film thickness in liquid face seals, Tribol Trans 51 (2) (2008) 140-149.

[26] A. Hunter, R.S. Dwyer-Joyce, P. Harper, Calibration and validation of ultrasonic reflection methods for thin-film measurement in tribology, Meas Sci Technol 23 (10) (2012).

[27] R. Boman, J.-P. Ponthot, Finite element simulation of lubricated contact in rolling using the arbitrary Lagrangian-Eulerian formulation, Comput Methods Appl Mech Eng 193 (39-41) (2004) 4323-4353. 